\title{
Development a New Carbon Nanocomposite Containing MWCNT as Adsorbent for Effective Removal of Cloxacillin
}

\section{Amir-Mohammad Golkarieh}

Islamic Azad University Science and Research Branch

Navid Nasirizadeh ( $\square$ nasirizadeh@iauyazd.ac.ir)

Islamic Azad University of Yazd https://orcid.org/0000-0002-4237-5164

Reza Jahanmardi

Islamic Azad University Science and Research Branch

Saeed Jafari

Islamic Azad University of Yazd

Mohammad Dehghani

Islamic Azad University of Yazd

\section{Research Article}

Keywords: Pharmaceutical Contaminants, MWCNT, Adsorbent, Sensor

Posted Date: August 3rd, 2021

DOI: https://doi.org/10.21203/rs.3.rs-703688/v1

License: (9) This work is licensed under a Creative Commons Attribution 4.0 International License. Read Full License 


\title{
Development a New Carbon Nanocomposite Containing MWCNT as adsorbent for Effective Removal of Cloxacillin
}

\author{
Amir-Mohammad Golkarieh ${ }^{1}$, Navid Nasirizadeh ${ }^{2 *}$, Reza Jahanmardi ${ }^{1}$, Saeed Jafari ${ }^{2}$, Mohammad Dehghani $^{2}$ \\ ${ }^{1}$ Department of polymer engineering, Science and research branch, Islamic Azad University, Tehran, Iran \\ ${ }^{2}$ Department of textile and polymer engineering, Yazd branch, Islamic Azad University, Yazd, Iran
}

Corresponding author: Navid Nasirizadeh, nasirizadeh@iauyazd.ac.ir

Fax number: +9835-3187-2280

\begin{abstract}
Antibiotics along with their metabolites due to their toxicity and low biodegradability have adverse effects to human and animal health. This work can help to monitor and elimination of the residue of the cloxacillin (Clox) antibiotics in two ways: the first part involves design and fabrication of a new electrochemical nanosensor based on a screen-printed carbon electrode modified with gold nanourchin and graphene oxide for detection and determination of Clox in aqueous media. The second part focuses on the preparation of carbon nanocomposites modified with multi-walled carbon nanotubes (MWCNT/CC) as adsorbent for the removal of Clox from aqueous medium. The MWCNT/CC nanocomposites were made using sol-gel process and then the efficiency of the antibiotic removal was assessed by the designed nanosensor. In Clox removal experiments, the effect of independent variables including $\mathrm{pH}$, exposure time, extent of MWCNTs and amount of adsorbent on the removal of antibiotic as a dependent variable was investigated using response surface methodology. The morphological and physical properties of the suggested adsorbent were explored. The maximum efficiency of Clox removal (97\%) was achieved in conditions of using $1.52 \mathrm{~g} / \mathrm{L}$ of the adsorbent fabricated by 2.9 wt. \% of MWCNTs in $0.1 \mathrm{M}$ phosphate buffer solution at $\mathrm{pH}$ of 5.0 during 75 minutes. The highest adsorption capacity of the MWCNT/CC was $296 \mathrm{mg} / \mathrm{g}$ at optimal conditions.
\end{abstract}

Keywords: Pharmaceutical Contaminants, MWCNT, Adsorbent, Sensor. 


\section{Introduction}

Cloxacillin (Clox) is a semi-synthetic antibiotic from the class of beta-lactamase-resistant penicillin. This antibiotic is only effective for bacterial infections and does not eliminate viral infections (such as the common cold and the flu) (Elmolla; 2009). Nowadays, excessive antibiotics utilization and subsequently, permeation of these chemicals into the groundwater and surface water resources have led to serious concerns worldwide. Usually, the residues of these drugs, along with their metabolites, enter the environment after digestion and metabolism in the human urine and faeces (Almakki; 2019). However, they may enter the environment via various ways, such as the wastewater streams of the pharmaceutical industries, hospitals and animals. The residues of these compounds due to their toxicity and low biodegradability have adverse effects on human health (Xiong; 2019). The presence of these substances not only causes problems in the process of wastewater treatment and the microbial ecology of surface water, but also results in resistant bacteria domination of other bacteria in the aeration tank of urban wastewater (Szymańska; 2019). The proliferation of antibiotic-resistant bacteria will disturb biological balance and cause unforeseen adverse effects on human and animals. In addition, the presence of antibiotics in wastewater treatment systems may inhibit the activity of sewage bacteria, which can seriously affect the decomposition of organic matter (Hernández; 2019). Due to the potential and actual risk of the pharmaceutical pollutants, awareness the amount of pollution and effective ways to eliminate it can help to preservation of the natural resources and environmental health (Pirsaheb; 2019). In the field of trace antibiotics removal from aqueous, numerous procedures have been recommended so far, such as UV irradiation (Pan; 2019), electrical coagulation (Grehs; 2019), nanofiltration (Lan; 2019), advanced oxidation techniques, such as photolysis (Cuerda-Correa; 2020), Fenton (Wang;2019), electrocatalytic degradation (Misal;2020), biological methods (Kumar; 2019) and adsorption 
(Jafari; 2019, Nasseh; 2019). These methods have their own advantages, but they have also disadvantages that make their applications difficult in most cases. For example, secondary pollutants are normally generated in physical methods such as coagulation and centrifugation (Bahrpaima; 2019), and in biological methods it takes a long time and the process efficiency is very low (Crini; 2019). Methods such as chlorination (Chang; 2019), ozonation (Gomes; 2019), advanced oxidation (Anawar; 2019), and nanofiltration (Completo; 2019) are also limited due to their high cost and inefficiency in the presence of antibiotics.

Adsorption is one of the commonly adopted approaches in treatment of water and wastewater that taken into consideration as a suitable method due to its low cost, high flexibility, easy design and handling, non-sensitive and high ability to remove toxic and hazardous substances (Wang; 2019, Esfandiyari; 2017). Various sorbents such as silica (Gounani; 2019), sepiolite (Wu; 2020), zeolite (Souza; 2020), bentonite (El Maataoui; 2019), chitosan (Mahmoud; 2020), activated carbon (Teixeira; 2019), clay (Premarathna; 2019) and agricultural wastes (cotton and sugarcane, corn cob, rice bran and coconut (Cukierman; 2019- Dai; 2020- Hasanzadeh; 2020) have been used to remove antibiotics from aqueous solutions.

Based on the above limitations, the manufacture of adsorbents with high absorption capacity and rapid recovery capability are required for fast and easy separation of pollutants. Nanotechnology with unique properties of nanoscale materials can solve this problem (Malakootian; 2019). One of the prominent features that has led to much attention being paid to the nanomaterials is believed to be their high surface-to-volume ratio. Nanoparticles can have high potential to absorb contaminants from polluted environments due to this eminent feature and other favorable properties (Noronha; 2019). The use of carbon nanotubes today has been widely investigated as a promising solution for the removal of various types of pollutants due to their high surface area, small, hollow and layered structures, flexibility and high elasticity (Xiang; 2019). 
Nevertheless, CNTs have been suggested to be separate difficultly because of their high diffusion capability and distribution in aqueous media. Accordingly, the resulting aqueous carbon colloids are able to enter any medium, and annihilate the cell wall via contact with skin or pass into both human and animal food chain (Mohanta; 2019). In order to avoid the dispersion of CNTs and their subsequent separation from aqueous media, various procedures have been offered including filtration (Yang; 2011), using chemicals (Zhang; 2019), magnetization (Masotti; 2013), embedment of CNTs in composite matrix (Kunde; 2019, Chae; 2019).

Hopefully, the carbon allotropes could be easily modified or combined with other materials to increase their absorption capacity and separate (Esfandiyari; 2017). Nanocomposites have better performance than their primary constituents. In the meantime, carbon composites have shown remarkable physical, mechanical, chemical and thermal properties (Yadav; 2019). Due to their structural porosity, these materials are lightweight and have a high specific surface area while maintaining high thermal stability (Ahmadi; 2016).

Electrochemical techniques based on modified electrodes due to their fast response and capability in being online, sensitivity and selectivity in tracing of elements and compounds are more popular than other measurement methods (Shojaei; 2016, Jafari; 2017). Modification or integration of nanoparticles such as graphene, CNTs or gold nanoparticles in the structure of electrodes can contribute to the precision, sensitivity and performance of electrochemical sensors (Jafari; 2021).

In this study, aiming to utilization of the exclusive features of MWCNTs in the adsorption of medicinal pollutants from water as well as resolving the problem of their dispersion in aqueous solutions, a novel MWCNTs-containing carbon nanocomposite has been designed and manufactured using silane polymers (sol-gel method). Optimization of antibiotic removal conditions by adsorption requires investigation of the effect of numerous experimental factors 
on the efficiency of the removal process. Response surface method (RSM) is a statistical technique by which through systematically performing a limited number of experiments, in addition to obtaining information on the effect of experimental variables on the response, one can also predict optimal operating conditions (Etemadifar; 2014). So far, RSM has been used to optimize the removal conditions of some antibiotics by adsorption (Okoli; 2019, Pirsaheb; 2019, Sarker; 2019).

In order to, detection and determination of trace Clox antibiotic in aqueous media during adsorption on carbon nanocomposite, a new electrochemical nanosensor was fabricated by immobilizing gold nanourchins (GNU) and graphene oxide (GO) nanolayer on screen-printed carbon electrode (SPCE) surface. This can expand the electron transfer rate and lead to availability of more Clox in the redox reaction due to agglomeration and catalytic activity of GNU and GO (Jafari; 2021). Also, RSM was applied to optimize the Clox removal from synthetic solutions polluted with Clox using MWCNTs modified carbon composite. For this purpose, the central composite design (CCD), which is one of the most widely used response surface designs, was implemented for assessing of effect of operational parameters such as MWCNTs amount for preparation of carbon composite, adsorbent dose, $\mathrm{pH}$ and contact time on the removal efficiency. The results of the CCD implementation were used to estimate the contribution of experimental factors and their interactions in response as well as to determine the optimal conditions. The kinetics and isothermal data of the adsorption of Clox antibiotic on MWCNTs/carbon composite (MWCNT/CC) surface were analyzed.

\section{Experimental}

\subsection{Chemicals and devices}

In the present experimental study, Cloxacillin (98\% purity, Scheme S1) antibiotic was purchased from Sigma-Aldrich (USA). Potassium trimethoxysilane, methanol, phosphoric acid 
and sodium hydroxide were obtained from Merck (Germany) and MWCNTs were received from NanoLab Co. (USA). Double-distilled water was used in all experiments to prepare aqueous solutions. The graphene oxide $(\mathrm{GO}, 3.0 \mathrm{mg} / \mathrm{mL})$ dispersion and gold nanourchins (GNU, $30 \mu \mathrm{g} / \mathrm{mL}$ in $\mathrm{H}_{2} \mathrm{O}$ ) were obtained from the Sigma-Aldrich (USA) to make an electrochemical nanosensor for the quantity of Clox.

Phosphoric acid and sodium hydroxide were used to adjust the $\mathrm{pH}$ of the solutions and a 827 model pH meter (Metrohm Autolab, Netherland) was applied for determination of solution $\mathrm{pH}$. The stirring of aqueous samples was performed using Fartest magnetic stirrer (Model HPMA 700, Farzaneh Arman Co., Ltd, Iran) and carbon composite as adsorbent powder was centrifuged by Eppendorf centrifuge device (MiniSpin, Germany). The concentration of Clox was determined using a potentiostat/galvanostat M101 $\mu$ Autolab type III model instrument (Metrohm Autolab, Netherland) attached to a designed electrochemical nanosensor by differential pulse voltammetry (DPV).

\subsection{Detection of Clox}

In the present research, an electrochemical nanosensor prepared by modifying a SPCE with GO/GNU nanocomposite layer in order to detect Clox. By a micropipette, a drop of $2.0 \mu \mathrm{L}$ of aqueous $\mathrm{GO}$ dispersion $(4.0 \mathrm{mg} / \mathrm{mL})$ with $\mathrm{pH}=7.0$ was deposited on the electrode surface and then dried in a moist chamber (scheme 2). Afterwards, the electrode was washed with distilled water and a drop of $1.0 \mu \mathrm{L}$ of GNU dispersion $(0.1 \mathrm{mg} / \mathrm{mL})$ was placed on the electrode surface. The procedure of preparing the modified sensor are illustrated in scheme S2.

In the DPV measurements of Clox, the electrochemical response of the designed sensor versus increment of Clox concentration in the solution was first assessed. Accordingly, several solutions containing certain concentrations of Clox were prepared and then analytical signal of the modified electrode were recorded in the prepared solutions by DPV. Next, a linear diagram of the electrochemical response of the designed sensor, namely, the oxidation current of Clox 
at the electrode surface, was depicted against the concentration of Clox. The obtained diagram was used to calculate the concentration of Clox in subsequent experiments.

In order to determine Clox concentration in the removal trials using prepared nanocomposites, at specified intervals, $5.0 \mathrm{~mL}$ samples from the solution that had been in contact with the adsorbent composite was transferred directly to the electrochemical cell and the response of the designed nanosensor was recorded. The residual concentration of Clox in solution was then calculated using the above-mentioned diagram.

\subsection{Fabrication of the suggested adsorbent nanocomposite}

In this study, the suggested adsorbent, namely, carbon nanocomposite, based on graphite modified with MWCNTs (MWCNT/CC) was made using a sol-gel process at room temperature according to previous studies (Esfandiyari, 2017). In brief, $20.0 \mu \mathrm{L}$ potassium trimethoxysilane was added to $4.0 \mathrm{~mL}$ of ethanol/water solution $(9: 1)(\mathrm{v} / \mathrm{v})$ (preparation of sol). The $\mathrm{pH}$ of the obtained solution was adjusted at 4.5 with the aid of $0.1 \mathrm{M} \mathrm{HCl}$ solution. Afterwards, the solution was stirred for 90 minutes using magnetic stirrer in order to hydrolyze the silanol compound. Subsequently, the color of the mixture became milky because of the hydrolysis of the silane compound and the silane network formation (formation of gel). A given volume of sol-gel mixture was then added to a specified homogenous mixture of MWCNTs/graphite with a certain weight ratio. A carbon paste was consequently formed, which was left at ambient temperature in order to evaporate the solvents. The dried paste was then posited for extra $2 \mathrm{~h}$ in an oven at $50{ }^{\circ} \mathrm{C}$ to be transformed into the carbon composite (MWCNT/CC), which was used as an adsorbent in the later stages.

\subsection{Optimization of Clox removal}

In order to achieve the highest antibiotic removal rate from aqueous solutions using the prepared carbon nanocomposites, independent variables including $\mathrm{pH}(2.0-11.0)$, contact time 
(20-120 min), MWCNTs' content in the carbon nanocomposite (0.1-5.0 wt $\%$ ) and amount of adsorbent (MWCNT/CC) in aqueous solutions $(0.2-1.0 \mathrm{~g} / \mathrm{L})$ was chosen and their effect on antibiotic removal rate was investigated. Antibiotic removal conditions were optimized by using the carbon nanocomposites based on response surface statistical method and a mathematical model was developed to predict Clox removal from the aqueous solutions. In fact, with the aid of this statistical method and with the least number of experiments, the simultaneous effect of all four independent variables and their interactions on antibiotic removal rate were studied thoroughly. The experimental design, statistical analysis of the obtained data and the mathematical modeling were performed using Design of Expert V.11 software package. Via introducing the variables and their studied range into the software (Table 1), 30 tests were proposed in order to optimize the removal efficiency, which are summarized in Table 2 together with their respective results.

\section{Table 1}

\section{Table 2}

At optimum conditions, $152 \mathrm{mg}$ of carbon nanocomposites (MWCNT/CC) containing $2.9 \mathrm{wt}$ $\%$ of MWCNTs was added to $100 \mathrm{~mL}$ of $0.1 \mathrm{M}$ phosphate buffer $(\mathrm{pH}=5.0)$ containing 10.0 ppm Clox $(10.0 \mu \mathrm{M})$ and stirred using a magnetic stirrer for 75 minutes at a speed of $500 \mathrm{rpm}$, in order to create a balance between the composite adsorbent and the Clox solution. The solution was then centrifuged for 10 minutes at $5000 \mathrm{rpm}$ to remove the carbon nanocomposite. Residual Clox in the solution was measured using a designed nanosensor by DPV. All experiments were repeated three times in order to increase the reliability and accuracy of the results, and the mean of the results was then reported. The efficiency of antibiotic removal (Clox Re) by carbon nanocomposite was calculated using the following equation:

$$
\operatorname{Clox} \operatorname{Re}(\%)=\frac{C_{0}-C_{t}}{C_{0}} * 100 \quad \text { Eq. (1) }
$$


In this equation $C_{0}$ is the initial concentration of Clox and $C_{t}$ is the actual antibiotic concentration in solution (after contact time of $\mathrm{t} \min$ ). In addition, the adsorption capacity of carbon nanocomposite $(Q)$ particles (mg of Clox absorbed per gram of nanocomposite) was calculated using the following equation:

$$
Q=\frac{\left(C_{0}-C_{t}\right) V}{m} \quad \text { Eq. (2) }
$$

where, $V$ is solution volume (L) and $m$ is used mass of the nanocomposite $(\mathrm{g})$.

\subsection{Modeling of adsorption kinetics and isotherms}

At this stage, experiments were performed by equilibrating $152 \mathrm{mg}$ of adsorbent (MWCNT/CC) containing $2.9 \%$ wt. MWCNTs in $100 \mathrm{~mL}$ Erlenmeyer flasks containing 10.0 ppm (100 mg/L) Clox solution at $\mathrm{pH}$ of 5.0. The mixture was shaken on a magnetic stirrer at $500 \mathrm{rpm}$ by keeping temperature constant $\left(25^{\circ} \mathrm{C}\right)$. At intervals of $5-120 \mathrm{~min}$, the residual Clox concentration was measured after sampling and separating of the adsorbent (based on Section 2-2).

Also, to investigate the equilibrium adsorption of Clox on sorbent, solutions with different initial concentrations of antibiotic; 30, 50, 80, 100, 120 and $150 \mathrm{mg} / \mathrm{L}$ were prepared at $\mathrm{pH}=$ 5.0 and after adding $152 \mathrm{mg}$ of carbon nanocomposites containing $2.9 \mathrm{wt} \%$ MWCNTs, solutions were placed on magnetic stirrer for 1 hour (equilibrium time). The concentration of residual Clox in the solution was also measured using the designed nanosensor in Section 2-2. Langmuir and Freundlich isotherms were used to analyze the equilibrium data and pseudofirst-order and pseudo-second-order models were also used to investigate the kinetics of the adsorption process. The constants of the adsorption kinetics and isotherm data were extracted to interpret the results, capacity, type and energy of the adsorption process.

\subsection{Study of structural properties of adsorbent}


Morphology of carbon composites containing MWCNTs was observed using a Mira 3-XMU model field emission scanning electron microscope (Tescan, Japan). $\mathrm{N}_{2}$ adsorption/desorption isotherms at $77{ }^{\circ} \mathrm{C}$ were utilized to determine pore diameter, porosity and total pore volume of the prepared carbon composites using a Belsorp analyzer (BEL Inc., Japan). The BrunauerEmmett-Teller (BET) method was also applied in order to ascertain specific surface area of the composites. Also, the zero-charge point $\left(\mathrm{pH}_{\mathrm{pzc}}\right)$ of the prepared adsorbent was determined using a Zetasizer 2000 model Zeta-meter instrument (Malvern, UK).

\section{Results and discussion}

\subsection{Characterization of the developed nanosensor}

Figs. S1A and S1B show SEM images of the surface of SPCE modified with GO and GNU/GO, respectively. As shown in Fig. (S1A), the surface of SPCE is roughened as a result of modification with GO, plate structure of which can be seen on the electrode surface. After immobilization of the GNU on the GO modified SPCE (Fig S1B), the effective electrode surface is increased, and therefore, their presence is anticipated to improve the electron transfer rate from the electrode surface, therewith enhancing the electrode sensitivity to Clox molecules. These results are consistent with the results of Sangili et al (2020) for surface modification of electrodes with graphene oxide / gold nanoparticles to increase surface area and improve electron transfer rate.

\subsection{Characterization of carbon nanocomposites modified with multi-walled carbon nanotubes (MWCNT-CC)}

The FESEM images of morphology of the carbon composite lacking MWCNTs (Fig 1A) and carbon nanocomposite containing MWCNT (fig 1B) are shown in Figure 1. As can be seen, the addition of MWCNT to the carbon composite has created numerous holes and porous 
structure in the carbon composite. This porous structure will be very effective in the adsorption process of antibiotics in aqueous.

TEM image taken from the carbon nanocomposites containing MWCNTs is exhibited in Fig. 1C. A bundle of carbon nanotubes outed from the surface of carbon nanocomposites is seen in the image. The presence of the nanotubes on the surface, ends of which are located inside the carbon matrix, significantly providing the nanocomposite's porosity, resulting in enlargement of the surface area and active sites essential for Clox adsorption. Similar findings have been reported on adsorbent containing CNTs by other researchers (Hudaib; 2018, Pourzamani; 2018).

Figure 1D shows the surface element analysis and elemental distribution (mapping) of the carbon nanocomposite modified with MWCNTs. Carbon, which is the main constituent of the porous structure of the designed composite in the present work, accounts for the highest percentage (79.8\%) and silicon and oxygen, which belong to the silane precursor for the preparation of sol-gel solution, are found to be less abundant on the surface of the carbon nanocomposite.

Fig 1.

The adsorption-desorption isothermal curves of unmodified carbon composite and carbon nanocomposites modified with MWCNTs are shown in Fig. 2. The curves show that the incorporation of carbon nanotubes in the carbon composite structure has increased the volume of adsorbed nitrogen gas sharply in the relative pressure region of 0.7 to 0.9 , which may be attributed to the capillary density inside the structure of the nanocomposite as well, decisively confirmed their mesoporous features (Sharifpour; 2020).

The calculations of the specific surface area, pore diameter and total pore volume were performed using BET method, the results of which are presented in Table 3. As the results of this table show, the texture properties of the nanocomposites have been greatly improved via 
the addition of MWCNTs to the carbon matrix. It can be deduced that specific surface area and pore diameter of the nanocomposites grew more than 4-fold because of using carbon nanotubes. The opening of the pore diameter can help more absorption of the antibiotic molecules onto the surface of the nanocomposite, thus, enhancing their removal from aqueous solutions.

\section{Table 3 .}

Overall, it can be stated that due to utilization of sol-gel method and the addition of MWCNTs for construction of carbon nanocomposite, the surface area, total pore volume, and average pore size of the active carbon treated with sol gel (composite without MWCNT) have increased dramatically. This may indicate the more porous structure of the composite surface (Esfandiyari; 2017). Although, mixing of MWCNT with AC using sol gel importantly decreased the adsorption/purification ability and surface area of the MWCNT; but CNTs can be easily separated after adsorption with the help of a paper filter.

To evaluated the surface charge of carbon nanocomposites modified with MWCNTs, the isoelectric point (a certain value of $\mathrm{pH}$ at which the net electric charge point is equal to zero) were determined via measurement of zeta potential in the $\mathrm{pH}$ range of $2-10$. The results are shown in Fig S2. The adsorbent's isoelectric point prepared was measured to be 5.4. This means that the surface charge of carbon nanocomposites at values below 5.4 is positive due to the protonation of functional groups such as hydroxyl on the surface of nanocomposites or oxygen at silanol network and conditions are provided for the adsorption of antibiotic anionic molecules in solution. The surface charge of the composite at $\mathrm{pH} \geq \mathrm{pH}_{\mathrm{pzc}}(\mathrm{pH}>5.4)$ is negative due to the removal of the proton from the negatively charged hydroxyl groups and creates a repulsive force between the antibiotic molecules (negative surface charge) and the adsorbent surface (. 


\subsection{FTIR study}

To probe the occurrence of the adsorption of antibiotic molecules on the functionalized groups of adsorbent FTIR spectroscopy were performed. FTIR spectra of prepared MWCNT/CC, as well as MWCNT/CC after the Clox adsorption process are presented in Fig 3 and Table S1. In the FTIR spectrum of MWCNT/CC, a characteristic absorption peak at $1143 \mathrm{~cm}^{-1}$ is evident corresponding to $\mathrm{COO}$ group, and a broad absorption peak is seen at $3357-3502 \mathrm{~cm}^{-1}$, which are assigned to $\mathrm{O}-\mathrm{H}$ stretching vibrations in the structure of the adsorbent nanocomposite. In the FTIR spectrum of the nanocomposites after the adsorption process of Clox, the of characteristic peaks of Clox, i.e. 3502, 3357, 1764, 1604, 1504, 1419, 1334 and $773 \mathrm{~cm}^{-1}$ are present (Schneider; 2018), which confirm the adsorption of Clox molecules onto the MWCNT/CC surface.

Fig 3.

\subsection{Detection of Clox using the modified electrode}

Electrochemical response of three types of SPCEs, namely, bare SPCE, GO-modified SPCE and GNU/GO/SPCE, to Clox was assessed by cyclic voltammetry (CV) technique, the results of which are shown in Fig. 4A. In this figure, the voltammograms are plotted in $0.1 \mathrm{M}$ phosphate-buffered solution in the presence of $0.1 \mathrm{mM}$ Clox. In the presence of Clox the bare SPCE shows an oxidation peak at $0.79 \mathrm{~V}$ with a current of around $0.4 \mathrm{nA}$ (curve a). Nonetheless, the current decreases by $0.05 \mathrm{nA}$ after immobilization of GO on the electrode surface, and the oxidation peak exhibits a partial shift to more positive potentials (curve b). One can infer that the modification of the electrochemical sensors by GO reduces surface conductivity or, equivalently, GO reduces electron transfer rate. After immobilization of GNU on the surface of GO-modified SPCE, the oxidation current of Clox is observed to be increased at the electrode surface and the oxidation peak demonstrates a shift to lower potentials. Thus, one can deduce that the desirable properties of GNU, especially their outstanding conductivity, 
play an important role in elevation of the surface conductivity and enhancing the electron transfer at the electrode surface (Jafari; 2021).

In order to evaluate the validity of the modification steps of the electrode, analytical responses of the modified and bare SPCEs, as electroactive probes, to $\mathrm{K}_{3}\left[\mathrm{Fe}(\mathrm{CN})_{6}\right](1.0 \mathrm{mM})$ were determined, the results of which are demonstrated in Fig. 4B. A perspicuous reversible CV peak pair at $0.27 \mathrm{~V}$ is observed in the $\mathrm{CV}$ responses of the bare SPCE probe (curve a). Nevertheless, it is seen that the modification of the SPCE with GO alleviated the reversible CV peak pair of the probe. (curve b). Moreover, the reduction and oxidation potentials of the probe is seen to be shifted to more positive and negative values, respectively. The presence of a negative charge on $\mathrm{GO}$, which exerts a repellent force to the negatively charged $[\mathrm{Fe}(\mathrm{CN})$ $\left.{ }_{6}\right]^{3-/ 4-}$, as well as the formation of an isolating layer by the GO, which hinders the $[\mathrm{Fe}(\mathrm{CN})$ 6] $]^{3-/ 4-}$ ions from approaching to the electrode surface can be regarded as the reasons of the observed phenomenon. Accordingly, the oxidation and reduction processes of the probe occur more difficultly.

It has been discerned that $\mathrm{GO}$, as a semiconductor, has a reducing effect on electricity, but, some other researchers presume electrocatalytic effects of $\mathrm{GO}$ to be more prominent (Dehghani; 2018, Azimzadeh; 2016, Jafari; 2018). The curve c in Fig 9, demonstrates significant augmentation of both cathodic and anodic partial currents of the probe after the modification of GO/SPCE with GNU. This can be attributed to various factors including substantial growth of the effective surface area of the electrode in the presence of the conductive nanoparticles as well as the outstanding electrical conductivity and the eminent electron transfer coefficient of gold (Hajihosseini; 2016, Aghili; 2017). As a result, the oxidation and reduction of the probe happens readily in the presence of GNU on the surface of the electrode. 
The behavior of the designed sensor was investigated at different Clox concentrations to appraise the sufficiency and performance of the sensor in Clox detection. Therefore, a GNU/GO-modified SPCE was prepared according to the mentioned procedure and then situated in a phosphorus solution $(0.1 \mathrm{M})$ at $\mathrm{pH}$ of 7.0 in the presence of various concentrations of Clox. Afterwards, DPVs of the sensor as operant electrodes were plotted for a threeelectrode set-up.

The results of the changes of the oxidation current of Clox on the surface of the GNU/GO/SPCE versus concentration of Clox in Fig. 4C show that there is a linear relationship at a relatively wide concentration range (20.0-950.0 nM) between the concentration of Clox and its oxidation current on the surface of the designed sensor. The following equation was used to evaluate the performance of the modified electrode to determine the detection limit of Clox (Zare; 2005):

$$
C_{m}=3 s_{b l} / m \quad \operatorname{Eq}(3)
$$

where, $s_{b l}$ represents the standard deviation of the measured currents for the GNU/GO modified SPCE in Clox-free solutions. Based on the slope of the diagram $\left(0.2867 \mu \mathrm{AnM}^{-1}\right)$, the detection limit of the developed sensor for determination of Clox is $8.0 \mathrm{nM}$.

In order to verify the feasibility of the developed method for Clox analyses in aqueous, the determination of Clox in solutions containing different amounts this antibiotic was carried out using the prepared electrochemical sensor. The recoveries of the spiked Clox, based on threeparallel detections, are listed in Table 4. The values of recoveries are found to be from 90.9 to $109.0 \%$, and \% RSD ranged from 1.4 to $6.2 \%$. As well, performance of the developed sensor was compared with HPLC, summarized in Table 4. This shows that the suggested sensor has a proper potential for the determination of Clox in aqueous samples, which was comparable to results obtained with HPLC.

\section{Table 4}

\subsection{Statistical modeling and validation}


The conditions of preparation and utilization of carbon nanocomposites with maximum removal efficiency were optimized based on response surface method and a mathematical model were modeled using the results to predict the amount of Clox removal using MWCNT/CC.

Statistical analysis of variance was applied to assess the significance and appropriateness of the proposed model by DOE software. Using the CCD and regression analysis of the data, the extracted model coefficients for the removal of Clox by the prepared nanocomposite are presented as coded values in Table 5 based on the variables of solution $\mathrm{pH}(\mathrm{A})$, the contact time of adsorbent with antibiotics solution (B), amount of MWCNTs for fabrication of the nanocomposite (C) and amount of carbon composite as adsorbent (D).

The analysis of variances (ANOVA) statistics for the achieved model was checked. As well, model compatibility and statistical significance were considered using the regained values for correlation coefficients $\left(\mathrm{R}^{2}\right)$. The proposed model can be considered to be statistically appropriate at $95 \%$ confidence level due to the p-value less than 0.0001 in the ANOVA table (Rahmati; 2021).

In order to analyze the statistical significance of all the expressions in the polynomial equation with $95 \%$ confidence level the $F$ test was used. The $F$ value obtained by this method represents the ratio of mean squares corresponding to the regression model and the errors, which equals to 15.93 . This is an indication of that the factors represent sufficiently variations of the data from their mean value and the factors effects in presented model are correct and true. On the other hand, differences in the experiments are sufficiently high, and the impact of errors is very low, therefore selected intervals of independent parameters are appropriate (Leili; 2020). The reported $F$ values for each factor as well as analysis of variance of the data indicate that the encoded factors A, B, C and D are independent variables affecting the removal efficiency of Clox by suggested carbon nanocomposites. In addition, the coefficients of interaction 
variables such as $\mathrm{AB}, \mathrm{AD}, \mathrm{BC}$ and $\mathrm{CD}$ and $\mathrm{A}^{2}$ and $\mathrm{C}^{2}$ are also significant. The results indicate that $\mathrm{A}^{2}, \mathrm{C}^{2}, \mathrm{D}$ and $\mathrm{BC}$ are the most influential factors on Clox removal efficiency and the amount of MWCNTs (C), the contact time (B) and solution pH stand next.

\section{Table 5.}

DOE software based on statistical modeling and data analysis gives a quasi-empirical equation for prediction of the Clox removal efficiency under the influence of the four parameters:

Clox $\operatorname{Re}(\%)=87.87-0.308 A-3.115 B+4.285 C+9.041 D+5.36 A B-1.157 A C+4.835 A D$ $+10.117 B C-2.15 B D+7.98 C D-21.18 A^{2}-6.031 B^{2}-18.926 C^{2}-3.32 D^{2} \quad$ (Eq. 4)

\subsection{The effect of operational parameters on Clox removal}

In this study, the RSM was used to determine the optimal conditions for removal of Clox using MWCNT/CC with maximum efficiency. In fact, with the help of this statistical method and with the least number of experiments, the simultaneous effects of all four parameters and their interactions on the antibiotic removal efficiency were studied comprehensively (Etemadifar; 2014). The results of this experiment are presented in Table 2. Also, Figure 5A shows changes in Clox removal efficiency as a function of solution $\mathrm{pH}$ and contact time of the carbon nanocomposite with the solution when the MWCNTs and the adsorbent amounts were fixed at $3.21 \% \mathrm{wt}$. and $1.31 \mathrm{~g} / \mathrm{L}$, respectively. It can be seen that by increasing $\mathrm{pH}$ in the range of 4.0 6.0, the removal efficiency of Clox using MWCNT/CC rises gently, but at higher $\mathrm{pH}$ values (6.1-10.0), the removal rate of Clox declines steeply.

The $\mathrm{pH}$ of the solution is an important factor determining the amount of contaminant adsorbed on the adsorbent (Shirgholami; 2017). It can be interpreted that the carboxylic groups (-COOH) in the Clox molecule transform to carboxylate (-COO-) in mildly acidic solutions and become anionic species. On the other hand, the $\mathrm{pH}_{\mathrm{pzc}}$ of MWCNT/CC was to be 5.4. Since, all adsorbents have positive charge at $\mathrm{pH}$ below $\mathrm{pH}_{\mathrm{pzc}}$ and negative at higher $\mathrm{pH}_{\mathrm{pzc}}$, in an aqueous 
environment with a $\mathrm{pH}$ between 2.8 and 5.4, the electrostatic attraction forces between the opposite charges of the negatively charged functional groups at Clox and the positively charges on carbon nanocomposites are the cause of the adsorption mechanism. In addition, by increasing the $\mathrm{pH}$ values to 6.1 and above, regarding the fact that the functional groups of antibiotics as well as the carbon nanocomposite are both negatively charged, rate of absorption of Clox by the adsorbent is significantly diminished. Therefore, it is recommended to use mild acidic to neutral $\mathrm{pH}$ (about 6.0) to remove this antibiotic with a developed adsorbent.

Alternatively, it is shown that with extending the contact time of the nanocomposites with the solution containing Clox in the range of 20 to 75 minutes, the antibiotic removal efficiency enhances from $25 \%$ to $55 \%$. The contact time of Clox molecules and adsorbent is another important factor affecting the adsorption process. There is a direct relationship between the contact time, adsorption capacity and removal efficiency. As there is a high availability of adsorption sites for antibiotic molecules in the early stages, the absorption of Clox is very quick. However, most adsorbent sites are occupied over time and reach to an equilibrium, hence, the removal process becomes slower. In fact, upon reaching equilibrium the adsorbent surface is saturated by Clox molecules and the adsorbent will not be able to absorb more Clox molecules. Similar outcomes have been described by Saha et al. So, it is clear from the graph that in 75 minutes, a considerable amount of antibiotic is absorbed and then reaches a nearly constant value.

The adsorption capacity of all used adsorbents increases with increasing time until a constant value is reached at a given time and an equilibrium is established. This means that rate of adsorption and desorption of Clox on the adsorbent surface is approximately equal. At this moment, the amount of absorbed Clox is dynamically in equilibrium with the amount of Clox desorbed. 
The results of effect of variations of the MWCNTs and the carbon nanocomposite amount on removal efficiency of Clox is shown graphically in Figure 5B. In this figure, the contact time and the $\mathrm{pH}$ of the solution are assumed to be constant at 67 min and 5.0; and amounts of MWCNTs and the nanocomposite change in the ranges of 0.5-4.5\% wt. and 0.1 -2.0 g/L, respectively. As can be seen in the figure, by increasing the amount of MWCNTs from 0.5 to $2.5 \%$ wt., the antibiotic removal efficiency increases from almost 25 to more than $65 \%$, but higher amounts of MWCNTs do not have positive effect on the removal efficiency.

On the other side of this three-dimensional diagram, it is shown effect of MWCNT/CC concentration on the removal rate of antibiotic from the solution. It is observed that Clox absorption onto the adsorbent and consequently removal of the antibiotic from the aqueous medium enhances with relatively constant slope through elevating the amount of MWCNT/CC from $0.5 \mathrm{~g} / \mathrm{L}$ to $1.45 \mathrm{~g} / \mathrm{L}$. Then, by increasing the adsorbent concentration to about $2.0 \mathrm{~g} / \mathrm{L}$, the removal efficiency levels out. It can be stated that the adsorbent surface has active sites for the adsorption of the suspended matter. Therefore, raising the amount of the consumed adsorbent augments number of active adsorption sites and ultimately, elevates removal efficiency (Tao; 2020). The enhancement of the process efficiency at lower values of the absorbent is more rapid, but beyond a certain concentration of the adsorbent $(1.52 \mathrm{~g} / \mathrm{L})$, the removal efficiency does not increase significantly and the adsorption process reaches equilibrium. This amount of adsorbent is considered as the optimum and economical dose of adsorbent.

The main objective of the optimization is to determine the optimum values of the variables to obtain the highest Clox removal efficiency using MWCNT/CC and with the aid of the model obtained from experimental data. The DOE software predicted that the highest removal efficiency of Clox (97\%) is achieved at $1.52 \mathrm{~g} / \mathrm{L}$ of the carbon nanocomposites modified by $2.9 \%$ wt of MWCNTs in $0.1 \mathrm{M}$ phosphate buffer solution at $\mathrm{pH}$ of 5.0 containing $10.0 \mu \mathrm{M}$ of 
Clox in 75 min. These conditions were used in subsequent tests, including adsorption kinetics and equilibrium.

\subsection{Removal efficiency of the Clox and adsorption capacity of the developed adsorbent}

In order to evaluate the adsorption capacity of MWCNT/CC for removal of Clox, solutions with certain concentrations of the antibiotic $(50,100$ and $150 \mathrm{ppm})$ were prepared. Then, 76 mg (1.52 g/L) of carbon nanocomposite modified with $2.9 \%$ wt MWCNTs was added to 50.0 $\mathrm{mL}$ of $0.1 \mathrm{M}$ phosphate buffer solution with $\mathrm{pH}=5.0$ containing Clox. The removal process was performed on the magnetic stirrer for a period of 100 minutes, which is slightly longer than the optimum time. After separating the nanocomposite from the solution, the concentration of Clox remaining in the solution was determined using a designed nanosensor by DPV. Efficiency of the antibiotic removal by the carbon nanocomposite and adsorption capacity (Q) of the carbon nanocomposite particles were calculated using equations 1 and 2 , respectively. Figure S3 shows kinetic data for removal of Clox from the aqueous medium, as percentage of its initial value, at different initial concentration of the antibiotic. It is seen that the percentage of Clox removal reaches to a same value of around $97 \%$ for all three Clox concentrations in 70 minutes. However, the initial rate of the antibiotic removal diminishes with increasing concentration of Clox. This may be interpreted in terms of constant number of adsorption sites on the carbon nanocomposite, which hinders proportional increase of the removal rate with rising initial Clox concentration. It should be noted that the removal data presented in Fig S3 are relative values with respect to initial Clox concentrations. This trend is in agreement with published data for adsorption process in similar studies (Esfandiyari; 2017, Jia; 2019).

The results of the kinetic measurement of adsorption of Clox by the carbon nanocomposite particles at different initial concentrations of the antibiotic are presented in Fig S4. According to the graph, the amount of Clox adsorption on the carbon nanocomposite particles reaches to the same value of $295 \mathrm{mg} / \mathrm{g}$, for all three Clox concentrations at the end of the test. Nonetheless, 
the period, over which this value is attained is shorter for the two highest concentrations. Furthermore, initial adsorption rate is observed to be enhanced with increasing initial concentration of Clox, which can be attributed to the increased probability of collision between the adsorbent and the adsorbate (Tao; 2020, Sharifpour; 2020).

The regeneration and reuse is one main parameters for adsorbents in order to investigate the stability of the synthesized composites. The stability of MWCNT/CC was considered reusability in six sequential reuse at constant parameters with $1.52 \mathrm{~g} / \mathrm{L}$ adsorbent prepared with $2.9 \%$ wt MWCNT, $50 \mathrm{mg} / \mathrm{L}$ Clox, $\mathrm{pH}$ of 5.0, 75 minutes. The suggested adsorbents were separated from the treated solution after each treatment by whatman cellulosic filter paper and washed using ultrapure water, dried and reused for consequent train (Fig.6). As shown in Fig. 6, six successive Clox-removal yields were found in $\% 95.5,90.7,86.5,78.1,70.1$, and $\% 67.8$ respectively. The achieved data in Fig. 6 exhibit the reusability of MWCNT/CC adsorbents for treatment of water polluted with Clox antibiotic. In similar studies stated that agglomeration of some of the particles may be results in the decrease of the reusability efficiency (Ghaedi; 2013). The comparison between specifications of some adsorbents for removal of antibiotics are listed in Table 6. The collected data in this table display The capacity and characteristics of the proposed adsorbent are comparable to other adsorbents used to remove antibiotics. Although the surface area of the proposed composite is less than that of multi-walled carbon nanotubes, the important point in this composite is the manufacturing method and the easy method of separating the adsorbent from the aqueous solution. The making method of this nanocomposite, i.e. sol gel procedure is easy and cheap, low temperature technique and low-risk procedures. It is able also to achieve uniform and small sized powders with sol gel method.

Regards to advantages of electrochemistry include easy to use and fast training, easy way to construction and or modifying of electrodes, excellent detection limits, with small analyte volumes, easy miniaturization, good selectivity, accuracy and speed of analysis; performance 
of electrochemical sensors is such that it can compete with conventional methods of antibiotic detection such as HPLC, EIS, GC-MS and so on (table 6). In this study; Clox detection sensor was fabricated using only 2 microliters of gold nanoparticles, 4 microliters of graphene oxide, and an inexpensive screen printed carbon electrode. Although the mentioned methods have high accuracy, sensitivity and selectivity, but their use requires expensive equipment and experienced labor. They also have a high analysis time and suffer from complicated and complex sample preparation steps and in some cases low sensitivity and selectivity.

\section{Table 6}

\subsection{Kinetics of the antibiotic adsorption}

Rate constant of the absorption of Clox on MWCNT/CC was determined through curve fitting of the obtained kinetic data to pseudo-first-order and pseudo-second-order kinetic models and the most suitable model was specified (Igberase; 2019). The results of data fitting, factors and correlation coefficients for the kinetic models are presented in Table 7. Comparison of the correlation coefficients obtained from the study of adsorption kinetics shows that highest determination coefficient $\left(\mathrm{R}^{2}\right)$ was achieved for the pseudo-second order model, 0.997, which verified that experimental data process of Clox adsorption follows pseudo-second-order kinetic model than pseudo-first-order model. Hereupon, we advise the dominant process in the adsorption of Clox on MWCNT/CC is physical but the occurrence of a little chemical adsorptions might be the key feature in controlling step. (Herrera-González; 2019, Zheng; 2019).

Table 7.

\subsection{Equilibrium adsorption study}


In order to analyze the results obtained through adsorption studies and their isotherms at equilibrium, two common and widely used models of the Langmuir and Freundlich equations were applied. The coefficients and constants of each of the Langmuir and Freundlich equations are illustrated in Table 8 . The data presented in table show that the adsorption process best fitted with Langmuir isotherm model and reveals the Clox absorption on the surface of the $\mathrm{MWCNT/CC}$ is monolayer.

As well, the criterion of $1 / \mathrm{n}$ was obtained between 0 and 1 , hence, it be able to said that the adsorbent surface is inhomogeneous (Ponnuchamy; 2020). This point out that the Freundlich model can also be applied to expression the adsorption model of the Clox on MWCNT/CC. Several studies have informed usage of both Freundlich and Langmuir isotherms for interpreting of the adsorption (Nandwani; 2019, Liu; 2016). Conversely, as it is seen in Table 8, correlation coefficient $\left(\mathrm{R}^{2}\right)$ of Langmuir model is greater compared with Freundlich isotherm, accordingly, Langmuir model is an ideal model for expression of behavior of Clox adsorption on MWCNT/CC. According to Langmuir model, the capacity of Clox adsorption on MWCNT/CC was considered to be $296 \mathrm{mg} / \mathrm{g}$.

\section{Table 8}

\subsection{Thermodynamic studies}

The Clox sorption behaviors at different concentrations onto MWCNT-CC were critically surveyed at $298,308,318$ and $328 \mathrm{~K}$, respectively. Accordingly, $\Delta \mathrm{S}^{\circ}$ and $\Delta \mathrm{H}^{\circ}$ can be obtained from the intercept and slope of the plot of $\ln K$ against reciprocal of absolute temperature, respectively (Fig S5) (Esfandiyari; 2017, Ye; 2019). The calculated thermodynamic parameters are illustrated in Table 9. It is seen that the both $\Delta \mathrm{H}^{\circ}$ and $\Delta \mathrm{S}^{\circ}$ values are positive. The positive $\Delta \mathrm{H}^{\circ}$ value, i.e. $3.046 \mathrm{~kJ} / \mathrm{mol}$, indicates that the adsorption process of Clox onto MWCNTCarbon composite is endothermic (Boukhalfa; 2019). This supports that removal efficiency of Clox on the adsorbent is also enhanced by increasing the temperature. This may be due to the 
increasing of molecular motions of the antibiotic in solution and increment of probability collision of the molecules with the adsorption sites on the adsorbent (Ghaedi; 2013).

On the other hand, the positive $\Delta \mathrm{S}^{\circ}$ value, i.e. $0.0686 \mathrm{~kJ} / \mathrm{molK}$, represents enhancement of the stochastic of the adsorption of Clox antibiotic at adsorbent-adsorbate interface. Furthermore, the adsorption process is confirmed to be spontaneous because of the negative $\Delta \mathrm{G}^{\circ}$ values. It is also seen that $\Delta \mathrm{G}^{\circ}$ value enhances with elevation of temperature, which reveals higher favorability of the Clox adsorption onto MWCNT-CC surface at low temperatures (Rocky; 2019).

\section{Table 9.}

\section{Conclusion}

In this study, a carbon nanocomposite was prepared using a sol-gel procedure and its capability as an adsorbent for Clox removal from aqueous solutions was studied. Moreover, for detection of Clox in such solutions, an electrochemical nanosensor was designed via modification of SPCEs with GO and GNU. The nanosensor was shown to be able to detect Clox in the concentration range of 20.0-950 $\mathrm{nM}$ with a quantitative detection limit of $8.0 \mathrm{nM}$. The surface structure and elemental analysis of the designed nanocomposite were investigated and the results showed presence of carbon, oxygen and silicon elements in the adsorbent structure with a of porous structure. MWCNTs were also observed on the adsorbent surface. The isoelectric point of the adsorbent, was shown to be 5.4, which was measured using zeta potential analysis. The operational conditions affecting the antibiotic removal process by the aid of the prepared nanocomposites such as solution $\mathrm{pH}$, amount of carbon nanocomposite as adsorbent, amount of carbon nanotubes in fabrication of the nanocomposite, and contact time were optimized using response surface methodology. The results of the statistical analysis and ANOVA showed that square of $\mathrm{pH}$ have the most effect on the adsorption of Clox. Effects of square of 
MWCNTs amount and adsorbent concentration are in the next order, respectively. The optimum conditions for separation of antibiotics from aqueous solutions were $\mathrm{pH}=5.0$, contact time of $75 \mathrm{~min}$, concentration of $1.52 \mathrm{~g} / \mathrm{L}$ of carbon nanocomposite modified with $2.9 \%$ wt of MWCNTs. Maximum removal of the antibiotic was predicted to be $97 \%$ in optimum conditions by DOE and the actual value of $95.35 \%$ was measured in the laboratory. Thermodynamics and kinetics of adsorption of Clox on MWCNT/CC were also studied. The adsorption behavior of the antibiotic at equilibrium and the adsorption kinetics were shown to be in accordance with the Langmuir isotherm and pseudo-second order model, respectively. Furthermore, the maximum adsorption capacity of the nanocomposite was determined to be $296 \mathrm{mg} / \mathrm{g}$. Determination of removal efficiencies proved that the nanocomposite is able to reduce the amount of the antibiotic content in aqueous media from $100 \mathrm{ppm}$ to less than $5 \mathrm{ppm}$.

\section{Acknowledgments}

The authors would like to thank the Science and research Branch, Islamic for the support of this research as well as Nanobiotechnology Research Center in Yazd Branch, Islamic Azad University for provide their lab.

\section{Compliance with Ethical Standards}

Conflict of Interest The authors declare that they have no conflict of interest.

Funding No funding was obtained for this study.

\section{Authors' contributions}

Amir-Mohammad Golkarieh: Material preparation and data collection;

Navid Nasirizadeh: Conceptualization, Supervision;

Reza Jahanmardi: Writing- Reviewing and Editing;

Saied Jafari: Data collection and analysis; 
Mohammad Dehghani: Data analysis and first draft of the manuscript;

All authors commented on previous versions of the manuscript.

All authors read and approved the final manuscript.

\section{Data Availability}

The data that support the findings of this study are available from the corresponding author [N. Nasirizadeh] upon reasonable request

\section{References}

Aghili Z, Nasirizadeh N, Divsalar A, Shoeibi S, Yaghmaei P (2017) A nanobiosensor composed of Exfoliated Graphene Oxide and Gold Nano-Urchins, for detection of GMO products. Biosens Bioelectron 95:72-80. https://doi.org/10.1016/j.bios.2017.02.054.

Ahmadi M, Jahanmardi R, Mohammadizade M (2016) Preparation of PMMA/MWNTs Nanocomposite Microcellular Foams by In-situ Generation of Supercritical Carbon Dioxide. Iran J Chem Chem Eng 35(2): 63-72. DOI: 10.30492/IJCCE.2016.19375.

Almakki A, Jumas-Bilak E, Marchandin H, Licznar-Fajardo P (2019) Antibiotic resistance in urban runoff. Sci Total Environ 667: 64-76. https://doi.org/10.1016/j.scitotenv.2019.02.183.

Anawar H M, Ahmed G (2019) Combined electrochemical-advanced oxidation and enzymatic process for treatment of wastewater containing emerging organic contaminants. In: Emerging and Nanomaterial Contaminants in Wastewater: Elsevier, pp. 277-307. https://doi.org/10.1016/B978-0-12-814673-6.00010-3.

Azimzadeh M, Rahaie M, Nasirizadeh N, Ashtari K, Naderi- Manesh H (2016) An electrochemical nanobiosensor for plasma miRNA-155, based on graphene oxide and gold nanorod, for early detection of breast cancer. Biosens Bioelectron 77: 99-106. DOI: 10.1016/j.bios.2015.09.020.

Babaei A A, Lima E C, Takdastan A, Alavi N, Goudarzi G, Vosoughi M, Hassani G, Shirmardi M (2016) Removal of tetracycline antibiotic from contaminated water media by multi-walled carbon nanotubes: operational variables, kinetics, and equilibrium studies. Water Sci Technol 74 (5): 1202-1216. doi: https://doi.org/10.2166/wst.2016.301.

Bahrpaima K, Fatehi P (2019) Preparation and Coagulation Performance of Carboxypropylated and Carboxypentylated Lignosulfonates for Dye Removal. Biomolecules 9(8): 383. https://doi.org/10.3390/biom9080383.

Boukhalfa N, Boutahala M, Djebri N, Idris A (2019) Kinetics, thermodynamics, equilibrium isotherms, and reusability studies of cationic dye adsorption by magnetic alginate/oxidized multiwalled carbon nanotubes composites. Int $J$ Biol Macromol 123: 539-548. https://doi.org/10.1016/j.ijbiomac.2018.11.102. 
Burmańczuk A, Grabowski T, Osypiuk M, Polska B, Kowalski C (2017) Determination of cloxacillin residues in dairy cows after intramammary administration. $\mathrm{J}$ vet Pharmacol Therap 40: 552 - 560. https://doi.org/10.1111/jvp.12391.

Cha JM, Yang S, Carlson KH (2006) Trace determination of $\beta$-lactam antibiotics in surface water and urban wastewater using liquid chromatography combined with electrospray tandem mass spectrometry. J Chromatogr A 1115:46-57. doi: 10.1016/j.chroma.2006.02.086.

Chae S, Noeiaghaei T, Oh Y, Kim IS, Park JS (2019) Effective removal of emerging dissolved cyanotoxins from water using hybrid photocatalytic composites. Water Res 149: 421-431. https://doi.org/10.1016/j.watres.2018.11.016.

Chang F, Shen S, Shi P, Zhang H, Ye L, Zhou Q, Pan Y, Li A (2019) Antimicrobial resins with quaternary ammonium salts as a supplement to combat the antibiotic resistome in drinking $\begin{array}{llll}\text { water treatment } & \text { 132-140. }\end{array}$ https://doi.org/10.1016/j.chemosphere.2019.01.047.

Completo C, Geraldes V, Semião V, Mateus M, Rodrigues M (2019) Comparison between microfluidic tangential flow nanofiltration and centrifugal nanofiltration for the concentration of small-volume samples. J Membrane Sci 578: 27-35. https://doi.org/10.1016/j.memsci.2019.02.022.

Crini G, Lichtfouse E (2019) Advantages and disadvantages of techniques used for wastewater treatment. Environ Chem Lett 17 (1):145-155. Doi:ff10.1007/s10311-018-0785-9ff.

Cuerda-Correa E M, Alexandre-Franco M F, Fernández-González C (2020) Advanced Oxidation Processes for the Removal of Antibiotics from Water: An Overview. Water 12(1):102. https://doi.org/10.3390/w12010102

Cukierman A L, Nunell G V, Bonelli P R (2019) Removal of emerging pollutants from water through adsorption onto carbon-based materials. In: Emerging and Nanomaterial Contaminants in Wastewater. Elsevier, pp. 159-213. DOI: 10.1016/B978-0-12-814673-6.00007-3.

Dai Y, Li J, Shan D (2020) Adsorption of tetracycline in aqueous solution by biochar derived from waste Auricularia auricula dregs. Chemosphere 238: 124432. https://doi.org/10.1016/j.chemosphere.2019.124432.

Dehghani M, Nasirizadeh N, Yazdanshenas M E (2019) Determination of cefixime using a novel electrochemical sensor produced with gold nanowires/graphene oxide/electropolymerized molecular imprinted polymer. Mater Sci Eng C 96: 654- 660. https://doi.org/10.1016/j.msec.2018.12.002.

El Maataoui Y, El M'rabet M, Maaroufi A, Dahchour A (2019) Spiramycin adsorption behavior on activated bentonite, activated carbon and natural phosphate in aqueous solution. Environ Sci Pollut Res 26(16): 15953-15972. https://doi.org/10.1007/s11356-019-05021-4.

Elmolla E, Chaudhuri M (2009) Optimization of Fenton process for treatment of amoxicillin, ampicillin and cloxacillin antibiotics in aqueous solution. J Hazard Mat 170: 666-672. DOI: 10.1016/j.jhazmat.2009.05.013.

Esfandiyari T, Nasirizadeh N, Dehghani M, Ehrampoosh M (2017) Graphene oxide based carbon composite as adsorbent for $\mathrm{Hg}$ removal: Preparation, characterization, kinetics and 
isotherm studies. Chinese J Chem $\quad$ Eng 25 (9):1170-1175. https://doi.org/10.1016/j.cjche.2017.02.006.

Esfandiyari T, Nasirizadeh N, Ehrampoosh M H, Tabatabaee M (2017) Characterization and absorption studies of cationic dye on multi walled carbon nanotube-carbon ceramic composite. J Ind Eng Chem 46: 35-43. https://doi.org/10.1016/j.jiec.2016.09.031.

Etemadifar A, Dehghanizadeh H, Nasirizadeh N, Rohani-Moghadam M (2014) Statistical optimization of wool dyeing with Alizarin Red S as a natural dye via central composite design. Fibers Polym 15(2): 254-260. https://doi.org/10.1007/s12221-014-0254-4.

Gomes J, Matos A, Gmurek M, Quinta-Ferreira R M, Martins R C (2019) Ozone and photocatalytic processes for pathogens removal from water: a review. Catalysts 9(1): 46. https://doi.org/10.3390/catal9010046

Gounani Z, Asadollahi M A, Pedersen J N, Lyngs J, Pedersen J S, Arpanaei A, Meyer R L (2019) Mesoporous silica nanoparticles carrying multiple antibiotics provide enhanced synergistic effect and improved biocompatibility. Colloids Sur B: Biointerfaces 175: 498-508. https://doi.org/10.1016/j.colsurfb.2018.12.035.

Grehs B W, Lopes A R, Moreira N F, Fernandes T, Linton M A, Silva A M, Manaia C M, Carissimi E, Nunes O C (2019) Removal of microorganisms and antibiotic resistance genes from treated urban wastewater: A comparison between aluminium sulphate and tannin coagulants. Water Res 166: 115056. https://doi.org/10.1016/j.watres.2019.115056

Hajihosseini S, Nasirizadeh N, Hejazi M S, Yaghmaei P (2016) A sensitive DNA biosensor fabricated from gold nanoparticles and graphene oxide on a glassy carbon electrode. Mater Sci Eng C 61: 506-515. https://doi.org/10.1016/j.msec.2015.12.091.

Hasanzadeh V, Rahmanian O, Heidari M (2020) Cefixime adsorption onto activated carbon prepared by dry thermochemical activation of date fruit residues. Microchemi J 152:1 04261. https://doi.org/10.1016/j.microc.2019.104261

Hernández F, Calısto-Ulloa N, Gómez-Fuentes C, Gómez M, Ferrer J, González-Rocha G, Montory M (2019) Occurrence of antibiotics and bacterial resistance in wastewater and sea water from the Antarctic. J Hazard Mat 363: 447-456. DOI: 10.1016/j.jhazmat.2018.07.027.

Herrera-González A M, Caldera-Villalobos M, Peláez-Cid A A (2019) Adsorption of textile dyes using an activated carbon and crosslinked polyvinyl phosphonic acid composite. J Environ Manag 234: 237-244. https://doi.org/10.1016/j.jenvman.2019.01.012.

Hudaib B, Gomes V, Shi J, Zhou C, Liu Z (2018) Poly (vinylidene fluoride)/polyaniline/ MWCNT nanocomposite ultrafiltration membrane for natural organic matter removal. Sep Purif Technol 190: 143-155. https://doi.org/10.1016/j.seppur.2017.08.026.

Igberase E, Ofomaja A, Osifo PO (2019) Enhanced heavy metal ions adsorption by 4aminobenzoic acid grafted on chitosan/epichlorohydrin composite: Kinetics, isotherms, thermodynamics and desorption studies. Int $\mathrm{J}$ Biol Macromol 123: 664-676. DOI: 10.1016/j.ijbiomac.2018.11.082.

Jafari S, Dehghani M, Nasirizadeh N, Akrami HR (2017) Voltammetric determination of Basic Red 13 during its sonoelectrocatalytic degradation. Microchim Acta 184: 4459-4468. https://doi.org/10.1007/s00604-017-2482-y. 
Jafari S, Dehghani M, Nasirizadeh N, Azimzadeh M (2018) An azithromycin electrochemical sensor based on an aniline MIP film electropolymerized on a gold nano urchins/graphene oxide modified glassy carbon electrode. J Electroanal Chem 829: 27-34. https://doi.org/10.1016/j.jelechem.2018.09.053.

Jafari S, Dehghani M, Nasirizadeh N, Azimzadeh M, Dehghan-banadaki F (2021). Electrochemical detection of bupropion drug using nanocomposite of molecularly imprinted polyaniline/Au nanoparticles/graphene oxide. Bull Mater Sci 44: 1-7. https://doi.org/10.1007/s12034-020-02348-4.

Jafari S, Dehghani M, Nasirizadeh N, Baghersad M H (2019) Synthesis and characterization of a selective adsorbent based on the molecularly imprinted polymer for the removal of cloxacillin antibiotic residue from milk. Int $\mathbf{J}$ Dairy Tech 72(4): 505-514. https://doi.org/10.1111/1471-0307.12620.

Jia X, Li S, Wang Y, Wang T, Hou X (2019) Adsorption behavior and mechanism of sulfonamide antibiotics in aqueous solution on a novel MIL-101 (Cr)@ GO composite. J Chem Eng Data 64(3): 1265-1274. https://doi.org/10.1021/acs.jced.8b01152.

Kumar M, Jaiswal S, Sodhi K K, Shree P, Singh D K, Agrawal P K, Shukla P (2019) Antibiotics bioremediation: Perspectives on its ecotoxicity and resistance. Environ Int 124:448-461. https://doi.org/10.1016/j.envint.2018.12.065.

Kunde GB, Sehgal B, Ganguli AK (2019) Synthesis of mesoporous rebar MWCNT/alumina composite (RMAC) nodules for the effective removal of methylene blue and $\mathrm{Cr}$ (VI) from an aqueous medium. J Hazard Mat 374: 140-151. https://doi.org/10.1016/j.jhazmat.2019.03.099.

Lan L, Kong X, Sun H, Li C, Liu D (2019) High removal efficiency of antibiotic resistance genes in swine wastewater via nanofiltration and reverse osmosis processes. J Environ Manag 231 :439-45. https://doi.org/10.1016/j.jenvman.2018.10.073.

Leili M, Shirmohammadi Khorram N, Godini K, Azarian G, Moussavi R, Peykhoshian A (2020) Application of central composite design (CCD) for optimization of cephalexin antibiotic removal using electro-oxidation process. J Mol Liq 313: 113556. https://doi.org/10.1016/j.molliq.2020.113556.

Li X, Miao J, Yin Z, Xu X, Shi H (2019) Polypyrrole-Modified Nylon 6 Nanofibers as Adsorbent for the Extraction of Two $\beta$-Lactam Antibiotics in Water Followed by Determination with Capillary Electrophoresis. Molecules (Basel, Switzerland) 24(12): 2198. https://doi.org/10.3390/molecules24122198

Liu P, Garrido B, Oksman K, Mathew AP (2016) Adsorption isotherms and mechanisms of Cu (II) sorption onto TEMPO-mediated oxidized cellulose nanofibers. RSC adv 6: 107759107767. https://doi.org/10.1039/C6RA22397D.

Mahmoud M E, El-Ghanam A M, Mohamed R H, Saad S R (2020) Enhanced adsorption of Levofloxacin and Ceftriaxone antibiotics from water by assembled composite of nanotitanium oxide/chitosan/nano-bentonite. Mater Sci Eng C 110199. https://doi.org/10.1016/j.msec.2019.110199

Malakootian M, Yaseri M, Faraji M (2019) Removal of antibiotics from aqueous solutions by nanoparticles: a systematic review and meta-analysis. Environ Sci Pollut Res 26(9): 84448458. https://doi.org/10.1007/s11356-019-04227-w. 
Masotti A, Caporali A (2013) Preparation of magnetic carbon nanotubes (Mag-CNTs) for biomedical and biotechnological applications. Int J Mol Sci 14(12): 24619-24642. DOI: 10.3390/ijms141224619.

Misal S N, Lin M H, Mehraeen S, Chaplin B P (2020) Modeling electrochemical oxidation and reduction of sulfamethoxazole using electrocatalytic reactive electrochemical membranes. J Hazard Mat 384: 121420. https://doi.org/10.1016/j.jhazmat.2019.121420.

Mohanta D, Patnaik S, Sood S, Das N (2019) Carbon nanotubes: Evaluation of toxicity at biointerfaces. J Pharm Anal 9 (5): 293-300. https://doi.org/10.1016/j.jpha.2019.04.003.

Najlaoui D, Echabaane M, Ben Khélifa A, Rouis A, Ben Ouada H (2019) Photoelectrochemical impedance spectroscopy sensor for cloxacillin based on tetrabutylammonium octamolybdate. J Solid State Electrochem 23: 3329-3341. https://doi.org/10.1007/s10008-019-04440-0.

Nandwani S K, Chakraborty M, Gupta S (2019) Adsorption of surface active ionic liquids on different rock types under high salinity conditions. Sci Rep 9(1): 1-16. https://doi.org/10.1038/s41598-019-51318-2.

Nasseh N, Barikbin B, Taghavi L, Nasseri M A (2019) Adsorption of metronidazole antibiotic using a new magnetic nanocomposite from simulated wastewater (isotherm, kinetic and $\begin{array}{lllll}\text { thermodynamic } & \text { studies). } & \text { Compos } & \text { B } & 159:\end{array}$ https://doi.org/10.1016/j.compositesb.2018.09.034.

Noronha V T, Aquino Y M, Maia M T, Freire R M (2019) Sensing of Water Contaminants: From Traditional to Modern Strategies Based on Nanotechnology. In: Nanomaterials Applications for Environmental Matrices. Elsevier, pp. 109-150. https://doi.org/10.1016/B9780-12-814829-7.00003-3.

Okoli C P, Ofomaja A E (2019) Development of sustainable magnetic polyurethane polymer nanocomposite for abatement of tetracycline antibiotics aqueous pollution: Response surface methodology and adsorption dynamics. J Clean Prod 217: 42-55. https://doi.org/10.1016/j.jclepro.2019.01.157.

Pan Y, Zhang Y, Zhou M, Cai J, Tian Y (2019) Enhanced removal of antibiotics from secondary wastewater effluents by novel UV/pre-magnetized $\mathrm{Fe} 0 / \mathrm{H}_{2} \mathrm{O}_{2}$ process. Water Res 153: 144-59. https://doi.org/10.1016/j.watres.2018.12.063.

Pirsaheb M, Moradi S, Shahlaei M, Wang X, Farhadian N (2019) A new composite of nano zero-valent iron encapsulated in carbon dots for oxidative removal of bio-refractory antibiotics from water. J Clean Prod 209: 1523-1532. https://doi.org/10.1016/j.jclepro.2018.11.175.

Ponnuchamy M, Kapoor A, Pakkirisamy B, Sivaraman P, Ramasamy K (2020) Optimization, equilibrium, kinetic and thermodynamic studies on adsorptive remediation of phenol onto natural guava leaf powder. Environ Sci Pollut Res 27: 20576-20597. https://doi.org/10.1007/s11356-019-07145-z.

Pourzamani H, Hajizadeh Y, Mengelizadeh N (2018) Application of three-dimensional electrofenton process using MWCNTs-Fe3O4 nanocomposite for removal of diclofenac. Process Saf Environ 119: 271-284. https://doi.org/10.1016/j.psep.2018.08.014.

Premarathna K S, Rajapaksha A U, Adassoriya N, Sarkar B, Sirimuthu N M, Cooray A, Ok Y S, Vithanage M (2019) Clay-biochar composites for sorptive removal of tetracycline antibiotic 
in aqueous media. J Environ Manag 238: 315-322. https://doi.org/10.1016/j.jenvman.2019.02.069.

Rahmati N, Rahimnejad M, Pourali M, Muallah Shatha K (2021) Effective removal of nickel ions from aqueous solution using multi-wall carbon nanotube functionalized by glycerol-based deep eutectic solvent. Colloids Interface Sci Commun 40: 100347. https://doi.org/10.1016/j.colcom.2020.100347.

Rocky K A, Pal A, Moniruzzaman M, Saha B B (2019) Adsorption characteristics and thermodynamic property fields of polymerized ionic liquid and polyvinyl alcohol based composite/CO $\mathrm{CO}_{2}$ pairs. J Mol Liq 294: 111555. https://doi.org/10.1016/j.molliq.2019.111555.

Saha BB, Uddin K, Pal A, Thu K (2020) Emerging sorption pairs for heat pump applications: an overview. JMST Adv 1: 161-180. https://doi.org/10.1007/s42791-019-0010-4.

Sangili A, Vinothkumar V, Chen SM, Veerakumar P, Lin KC (2020) Gold Nanoparticle Embedded on a Reduced Graphene Oxide/polypyrrole Nanocomposite: Voltammetric Sensing of Furazolidone and Flutamide. Langmuir 36:13949-13962. https://doi.org/10.1021/acs.langmuir.0c02448.

Sarker K N, Mohapatra P K, Dutta S (2019) Use of low cost natural resources for enhanced chitinase production and optimization using CCD and RSM: a new initiative for bio-control of plant pathogen. Indian Phytopathol 72(2): 281-300. https://doi.org/10.1007/s42360-01900143-8.

Schneider R, Mercante L A, Andre R S, Brandão H D M, Mattoso L H, Correa D S (2018) Biocompatible electrospun nanofibers containing cloxacillin: Antibacterial activity and effect of $\mathrm{pH}$ on the release profile. React Funct Polym 132: 26-35. https://doi.org/10.1016/j.reactfunctpolym.2018.09.001.

Sharifpour N, Moghaddam FM, Mardani G, Malakootian M (2020) Evaluation of the activated carbon coated with multiwalled carbon nanotubes in removal of ciprofloxacin from aqueous solutions. Appl Water Sci 10: 140-146. https://doi.org/10.1007/s13201-020-01229-9

Shirgholami M A, Mirjalili M, Nasirizadeh N (2017) Preparation of A MWCNT-Graphite Composite Based on Sol Gel Method for Dye Removal. Orient J Chem 33 (2) 676-685. http://dx.doi.org/10.13005/ojc/330215.

Shojaei S, Nasirizadeh N, Entezam M, Koosha M, Azimzadeh M (2016) An Electrochemical Nanosensor Based on Molecularly Imprinted Polymer (MIP) for Detection of Gallic Acid in Fruit Juices. Food Anal Method 9: 2721-2731. https://doi.org/10.1007/s12161-016-0459-9.

Souza I M, Sainz-Díaz C I, Viseras C, Pergher S B (2020) Adsorption capacity evaluation of zeolites as carrier of isoniazid. Microporous Mesoporous Mat 292: 109733. https://doi.org/10.1016/j.micromeso.2019.109733

Szymańska U, Wiergowski M, Sołtyszewski I, Kuzemko J, Wiergowska G, Woźniak M K (2019) Presence of antibiotics in the aquatic environment in Europe and their analytical monitoring: recent trends and perspectives. Microchem J 147: 729-740. https://doi.org/10.1016/j.microc.2019.04.003.

Tao J, Yang J, Ma C, Li J, Du K, Wei Z, Chen C, Wang Z, Zhao C, Deng X (2020) Cellulose nanocrystals/graphene oxide composite for the adsorption and removal of levofloxacin 
hydrochloride antibiotic from aqueous solution. $\mathrm{R}$ Soc open sci 7:1-24. http://doi.org/10.1098/rsos.200857

Teixeira S, Delerue-Matos C, Santos L (2019) Application of experimental design methodology to optimize antibiotics removal by walnut shell based activated carbon. Sci Total Environ 646: 168-176. https://doi.org/10.1016/j.scitotenv.2018.07.204.

Wang J, Zhou X, Gatheru Waigi M, Owino Gudda F, Cheng P, Ling W(2019) Simultaneous Removal of Estrogens and Antibiotics from Livestock Manure Using Fenton Oxidation Technique. Catalysts 9(8): 644. https://doi.org/10.3390/catal9080644.

Wang N, Xiao W, Niu B, Duan W, Zhou L, Zheng Y (2019) Highly efficient adsorption of fluoroquinolone antibiotics using chitosan derived granular hydrogel with 3D structure. J Mol Liq 281: 307-314. https://doi.org/10.1016/j.molliq.2019.02.061

Wu J, Wang Y, Wu Z, Gao Y, Li X (2019) Adsorption properties and mechanism of sepiolite modified by anionic and cationic surfactants on oxytetracycline from aqueous solutions. Sci Total Environ 708: 134409. https://doi.org/10.1016/j.scitotenv.2019.134409

Xiang Y, Xu Z, Wei Y, Zhou Y, Yang X, Yang Y, Yang J, Zhang J, Luo L, Zhou Z (2019) Carbon-based materials as adsorbent for antibiotics removal: mechanisms and influencing factors. J Environ Manag 237: 128-138. https://doi.org/10.1016/j.jenvman.2019.02.068.

Xiong J Q, Kim S J, Kurade M B, Govindwar S, Abou-Shanab R A, Kim J R, Jeon B H (2019) Combined effects of sulfamethazine and sulfamethoxazole on a freshwater microalga, Scenedesmus obliquus: toxicity, biodegradation, and metabolic fate. J Hazard Mat 370: 138146. https://doi.org/10.1016/j.jhazmat.2018.07.049.

Xiong W, Zeng G, Yang Z, Zhou Y, Zhang C, Cheng M, Liu Y, Hu L, Wan J, Zhou C, Xu R, Li X (2018) Adsorption of tetracycline antibiotics from aqueous solutions on nanocomposite multi-walled carbon nanotube functionalized MIL-53(Fe) as new adsorbent. Sci Total Environ 627: 235-244. https://doi.org/10.1016/j.scitotenv.2018.01.249.

Yadav V B, Gadi R, Kalra S (2019) Clay based nanocomposites for removal of heavy metals from water: a review. J Environ Manag 232: 803-817. https://doi.org/10.1016/j.jenvman.2018.11.120.

Yang ST, Wang H, Wang Y, Wang Y, Nie H, Liu Y (2011) Removal of carbon nanotubes from aqueous environment with filter paper. Chemosphere 82(4): 621-626. https://doi.org/10.1016/j.chemosphere.2010.10.048.

Ye Y, Jiao J, Kang D, Jiang W, Kang J, Ngo HH, Guo W, Liu Y (2019) The adsorption of phosphate using a magnesia-pullulan composite: Kinetics, equilibrium, and column tests. Environ Sci Pollut Res 26(13): 13299-13310. https://doi.org/10.1007/s11356-019-04858-z.

Zare H R, Nasirizadeh N, Ardakani M M (2005) Electrochemical properties of a tetrabromop-benzoquinone modified carbon paste electrode: Application to the simultaneous determination of ascorbic acid, dopamine and uric acid. J Electroanal Chem 577(1): 25-33. https://doi.org/10.1016/j.jelechem.2004.11.010.

Zhang M, Deng Y, Yang M, Nakajima H, Yudasaka M, Iijima S, Okazaki T (2019) A simple method for removal of carbon nanotubes from wastewater using hypochlorite. Sci rep 9(1): 17. https://doi.org/10.1038/s41598-018-38307-7. 
Zheng M, Zhao X, Wang K, She Y, Gao Z (2019) Highly efficient removal of Cr(VI) on a stable metal-organic framework based on enhanced H-bond interaction. Ind Eng Chem Res 58: 23330-23337. https://doi.org/10.1021/acs.iecr.9b04598. 


\section{Figure Caption:}

Fig. 1. FESEM images of the A) carbon composite without MWCNTs and B) carbon nanocomposite containing MWCNTs, $C$ ) TEM image and D) Elemental analysis and mapping diagram of carbon nanocomposites containing MWCNTs.

Fig 2. Diagram of $\mathrm{N}_{2}$ absorption-desorption for a) unmodified carbon composite, the inset is the calculated pore diameter distribution. b) MWCNTs-modified carbon nanocomposite. The insert is the calculated pore diameter distribution.

Fig 3. FTIR spectra of the MWCNT/CC before (A) and after (B) adsorption of Clox.

Fig 4. A) Cyclic voltammograms of modified SPCE in a solution containing $0.1 \mathrm{mM}$ of Clox in phosphate buffer with $\mathrm{pH}=7.0$. a) bare SPCE, b) GO modified SPCE, c) GNU/GO SPCE. B) $\mathrm{CV}$ responses of the SPCE in $1.0 \mathrm{mM}[\mathrm{Fe}(\mathrm{CN}) 6] 3-/ 4-$ in a $0.1 \mathrm{M}$ phosphate buffer $(\mathrm{pH}$ 7.0) for (a) the bare SPC electrode, (b) GO/SPCE, and (c) GNU/GO/SPCE. C) Differential pulse voltammograms of GNU/GO modified SPCE in the presence of different concentrations of Clox (20.0 -950.0 nM) in 0.1 M buffer solution pH 7.0. D) Diagram of current variations in terms of concentration of Clox (20.0 -950.0 nM).

Fig 5. Three-dimensional response surface plots for interactive effect of the A) $\mathrm{pH}(4.0-10.0)$ and contact time $(20-120 \mathrm{~min})$ at $3.21 \%$ wt MWCNT and $1.31 \mathrm{~g} / \mathrm{L}$ MWCNT/CC, B) MWCNTs $(0.5-4.5 \% \mathrm{wt})$ and carbon nanocomposite $(0.5-1.8 \mathrm{~g} / \mathrm{L})$ on removal efficiency at the $\mathrm{pH}=5.0$ and contact time $67 \mathrm{~min}$.

Fig. 6. Cycle stability of MWCNT/CC during 6 cycle for Clox adsorbent. 
Fig. 1.

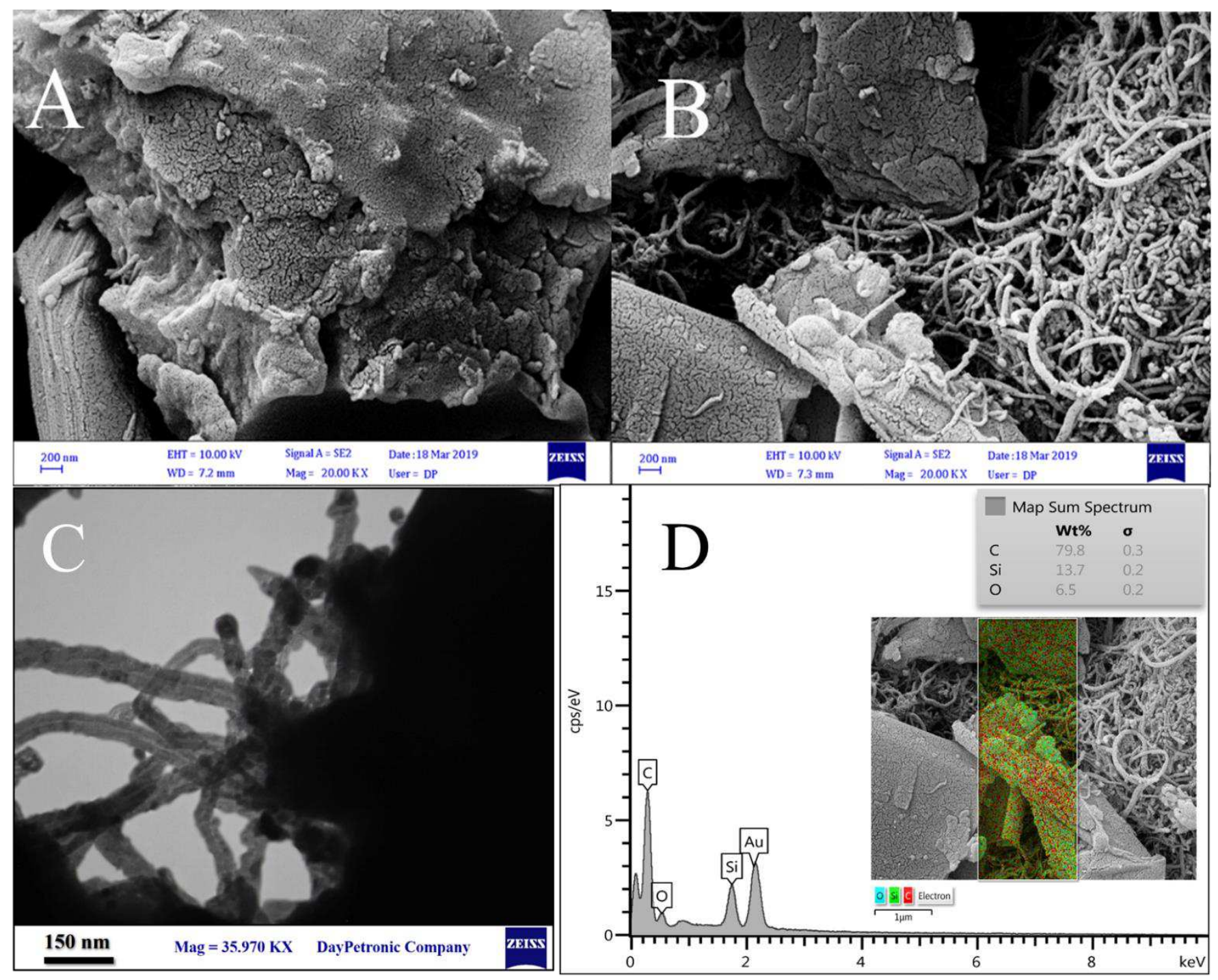


Fig. 2.
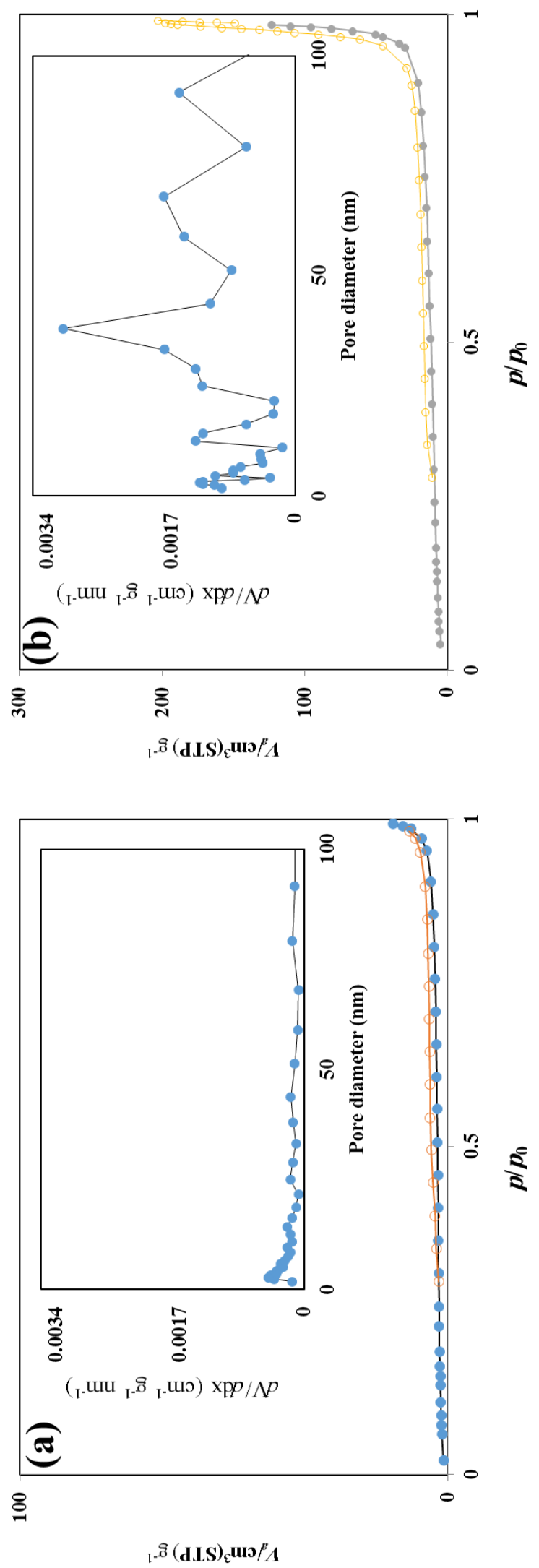
Fig. 3.

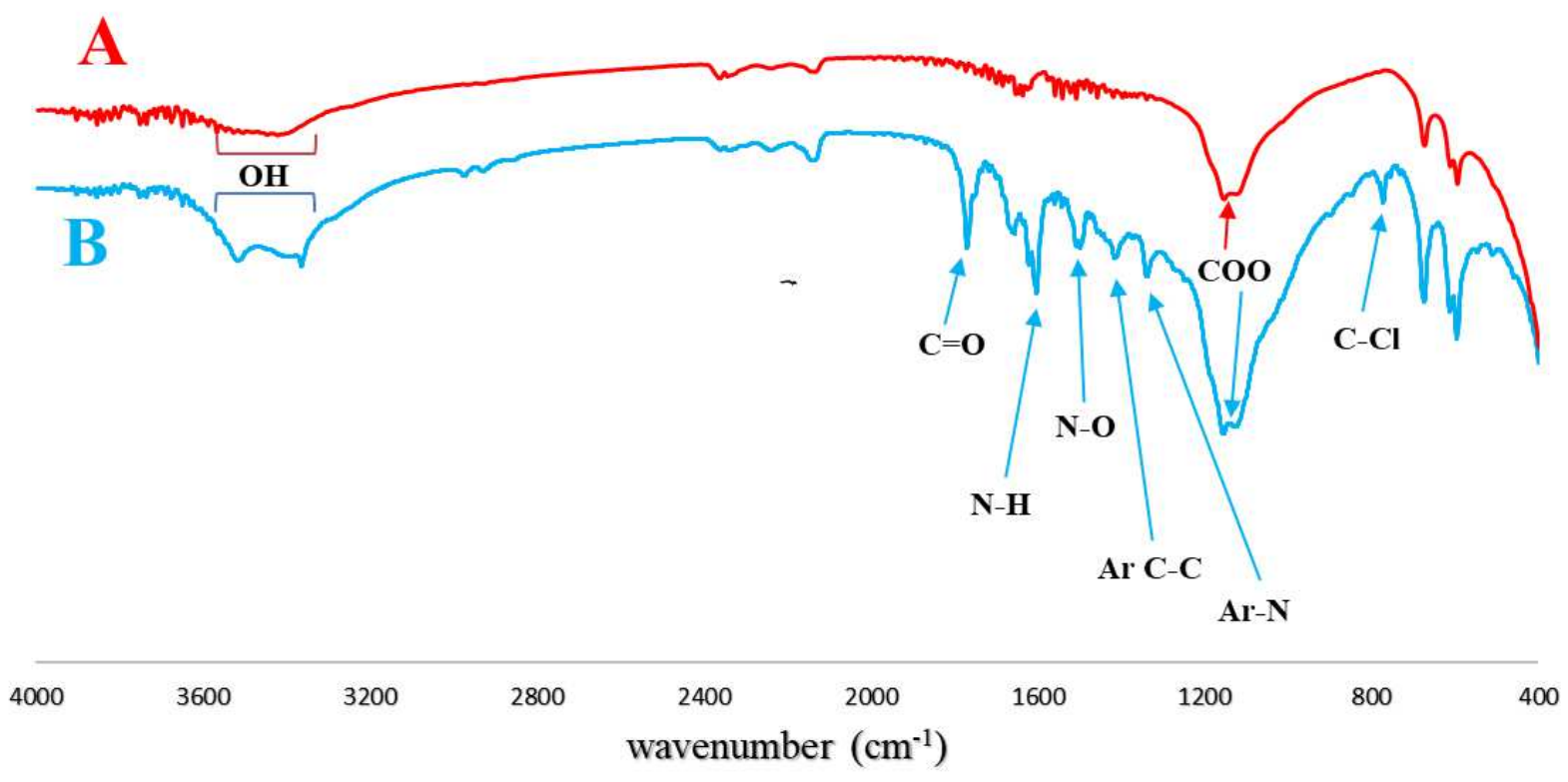


Fig. 4.
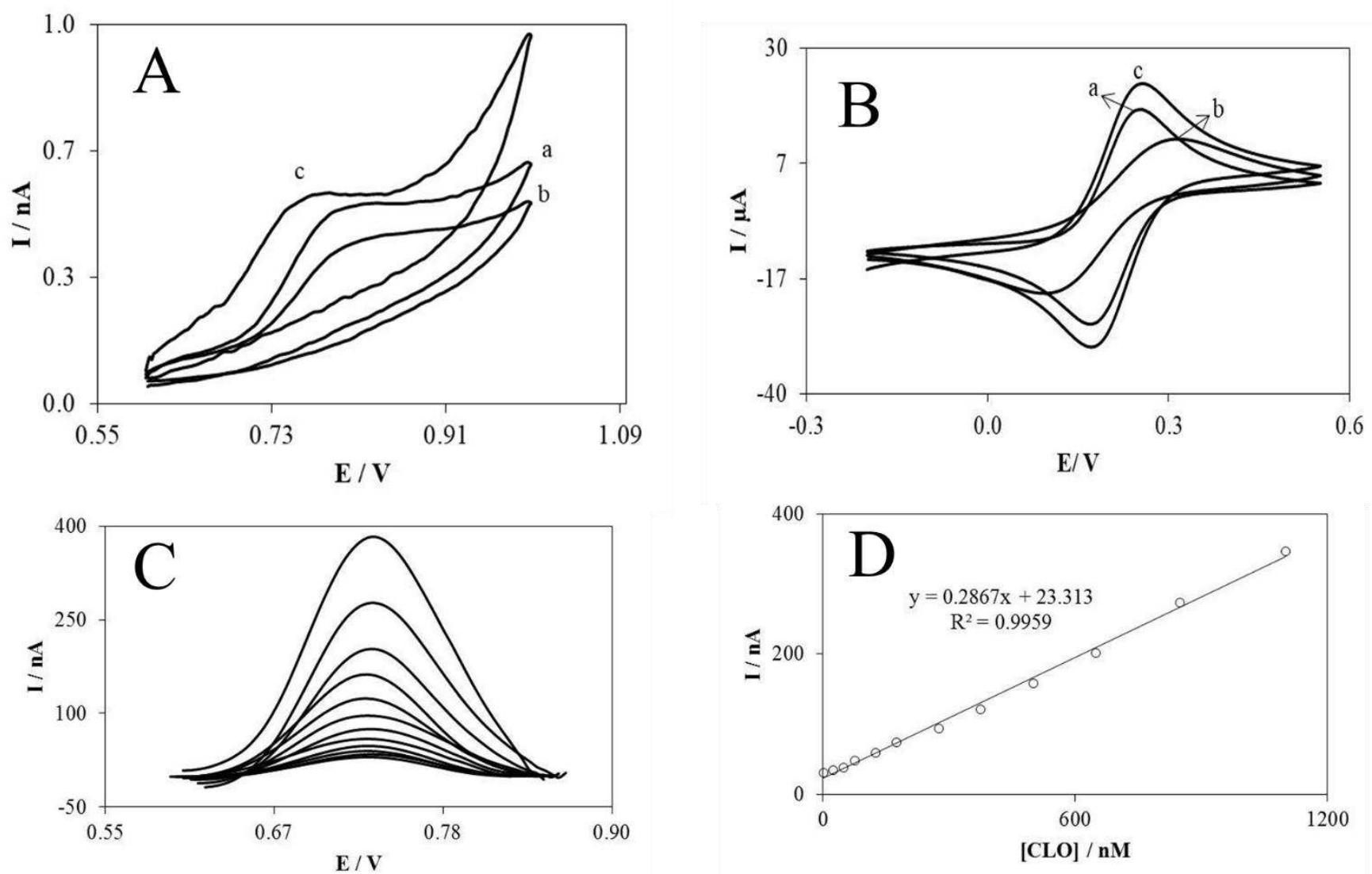
Fig. 5.

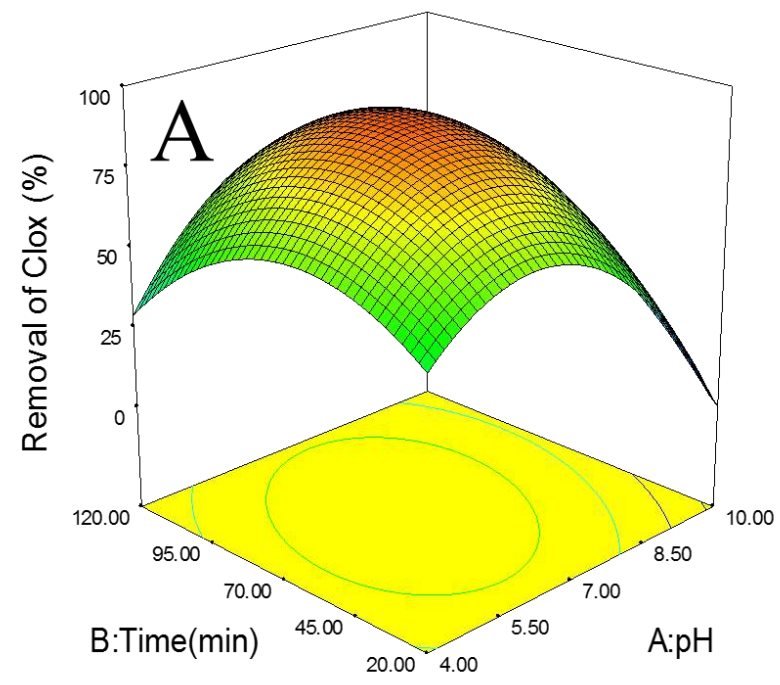

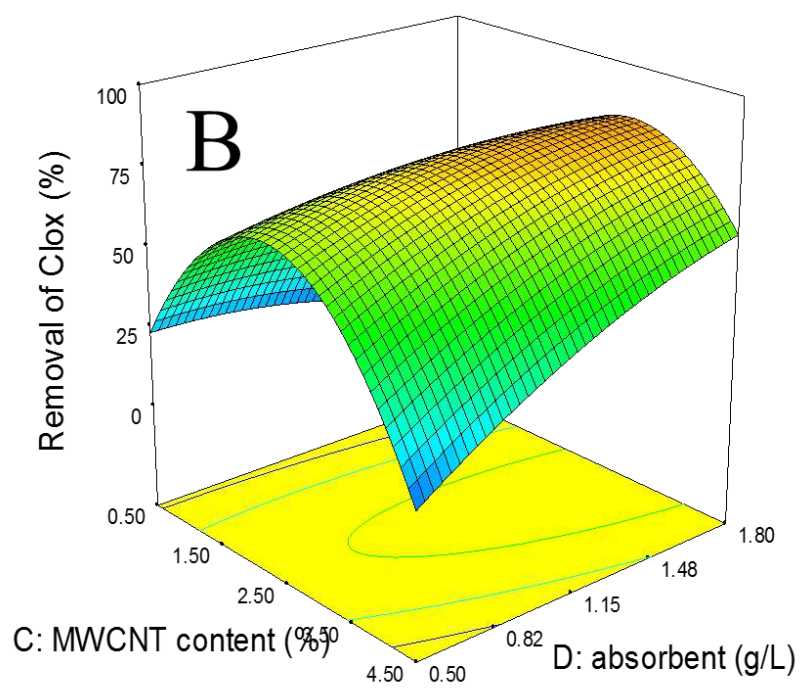


Fig. 6 .

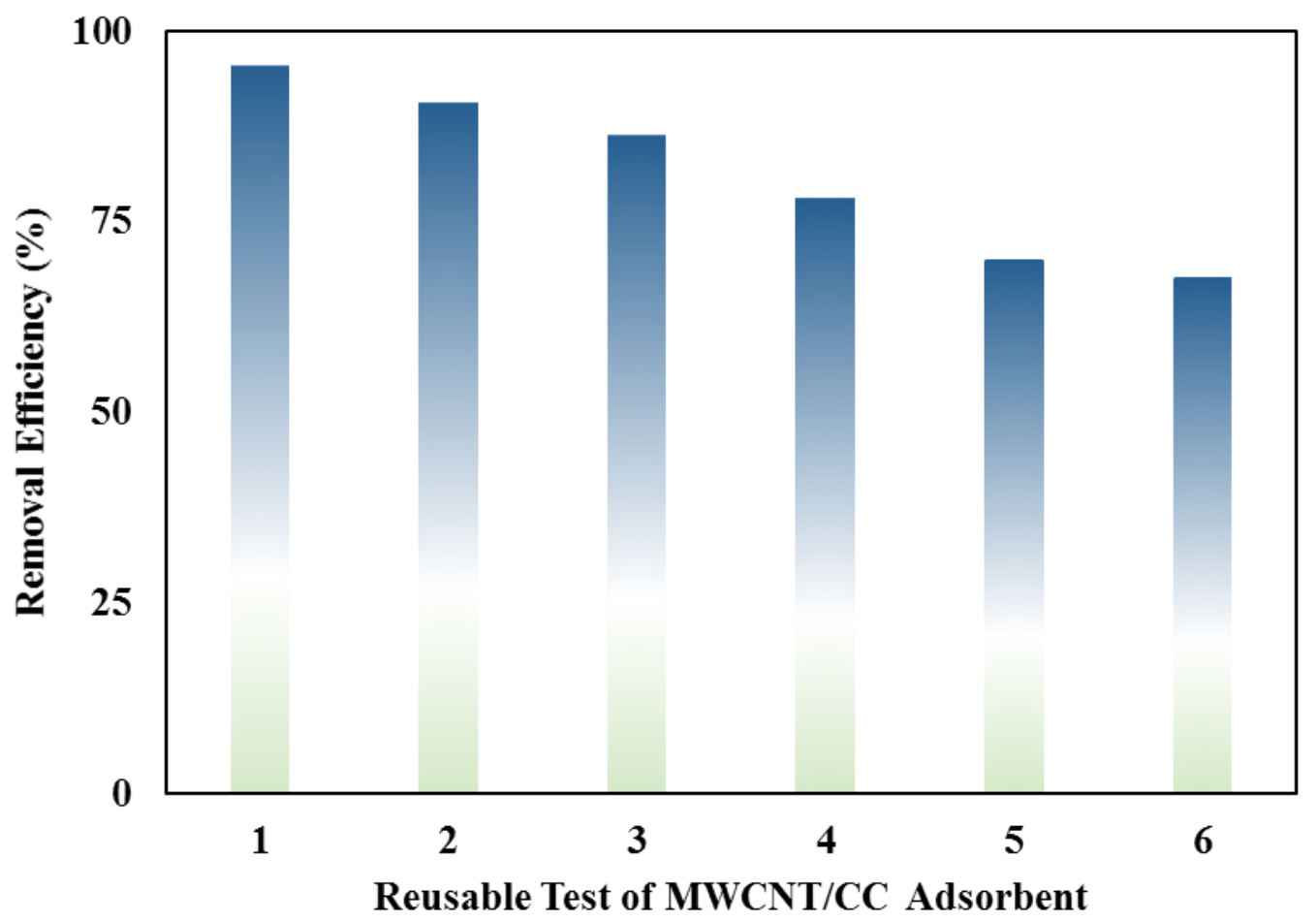


Table 1 Experimental range and levels of the independent variables.

\begin{tabular}{cccccccc}
\hline \multirow{2}{*}{ Parameters } & \multirow{2}{*}{ Unit } & \multirow{2}{*}{ Symbol } & \multicolumn{5}{c}{ Levels } \\
\cline { 5 - 8 } $\mathrm{pH}$ & - & $\mathrm{A}$ & 2 & 4.25 & 6.5 & 8.75 & 11 \\
Time & $\mathrm{Min}$ & $\mathrm{B}$ & 20 & 45 & 70 & 95 & 120 \\
MWCNT & $\mathrm{Wt} \%$ & $\mathrm{C}$ & 0.1 & 1.325 & 2.55 & 3.775 & 5 \\
MWCNT-CC & $\mathrm{g} / \mathrm{L}$ & $\mathrm{D}$ & 0.1 & 0.33 & 0.55 & 0.75 & 1 \\
\hline
\end{tabular}


Table 2- Experimental design based on Central Composite design (CCD) used in the present study.

\begin{tabular}{|c|c|c|c|c|c|}
\hline Run & A:pH & $\begin{array}{l}\text { B: } \\
\text { time } \\
(\min )\end{array}$ & $\begin{array}{c}\text { C:MWCNT } \\
\text { (\%wt) }\end{array}$ & $\begin{array}{c}\text { D: } \\
\text { MWCNT/CC } \\
(\mathrm{g} / \mathrm{L})\end{array}$ & $\begin{array}{c}\text { Clox } \\
\text { Removal } \\
(\%)\end{array}$ \\
\hline 1 & 6.5 & 70 & 2.55 & 1.05 & 87 \\
\hline 2 & 6.5 & 70 & 2.55 & 2 & 94 \\
\hline 3 & 4.25 & 45 & 1.325 & 1.525 & 45 \\
\hline 4 & 6.5 & 20 & 2.55 & 1.05 & 82 \\
\hline 5 & 8.75 & 95 & 3.775 & 0.575 & 27 \\
\hline 6 & 6.5 & 70 & 2.55 & 1.05 & 80 \\
\hline 7 & 6.5 & 120 & 2.55 & 1.05 & 50 \\
\hline 8 & 8.75 & 95 & 1.325 & 0.575 & 21 \\
\hline 9 & 4.25 & 45 & 1.325 & 0.575 & 43 \\
\hline 10 & 8.75 & 95 & 1.325 & 1.525 & 29 \\
\hline 11 & 6.5 & 70 & 2.55 & 0.1 & 58 \\
\hline 12 & 11 & 70 & 2.55 & 1.05 & 13 \\
\hline 13 & 6.5 & 70 & 2.55 & 1.05 & 84 \\
\hline 14 & 4.25 & 95 & 1.325 & 1.525 & 18 \\
\hline 15 & 8.75 & 45 & 3.775 & 1.525 & 43 \\
\hline 16 & 4.25 & 95 & 3.775 & 1.525 & 45 \\
\hline 17 & 8.75 & 95 & 3.775 & 1.525 & 90 \\
\hline 18 & 6.5 & 70 & 2.55 & 1.05 & 88 \\
\hline 19 & 8.75 & 45 & 3.775 & 0.575 & 20 \\
\hline 20 & 6.5 & 70 & 2.55 & 1.05 & 96 \\
\hline 21 & 6.5 & 70 & 0.1 & 1.05 & 15.2 \\
\hline 22 & 4.25 & 45 & 3.775 & 1.525 & 64 \\
\hline 23 & 8.75 & 45 & 1.325 & 1.525 & 42 \\
\hline 24 & 4.25 & 95 & 1.325 & 0.575 & 20 \\
\hline 25 & 8.75 & 45 & 1.325 & 0.575 & 35 \\
\hline 26 & 6.5 & 70 & 5 & 1.05 & 24 \\
\hline 27 & 4.25 & 95 & 3.775 & 0.575 & 45 \\
\hline 28 & 6.5 & 70 & 2.55 & 1.05 & 86 \\
\hline 29 & 4.25 & 45 & 3.775 & 0.58 & 18 \\
\hline 30 & 2 & 70 & 2.55 & 1.05 & 9 \\
\hline
\end{tabular}


Table 3. Textural properties obtained by $\mathrm{N}_{2}$ adsorption/desorption studies.

\begin{tabular}{llll}
\hline Parameter & Technique & CC & MWCNT/CC \\
\hline BET surface area $\left(\mathrm{m}^{2} / \mathrm{g}\right)$ & BET $^{\mathrm{a}}$ & 7.285 & 31.377 \\
${\text { Pore volume }\left(\mathrm{cm}^{3} / \mathrm{g}\right)}$ BJH adsorption $^{\mathrm{b}}$ & 0.017 & 0.307 \\
Pore diameter $\left.(\AA)^{\mathrm{A}}\right)$ & BJH adsorption $^{\mathrm{b}}$ & 9.671 & 39.215
\end{tabular}

a Computed in the P/P0 range of 0.05-0.50.

b BJH (Barrett Joyner Halenda) cumulative adsorption pore volume for pores in range of 0 and $50.0 \AA$ diameter. 
Table 4. Determination of Clox in spiked aqueous, proposed sensor and HPLC method.

\begin{tabular}{cccccccc}
\hline \multirow{2}{*}{$\begin{array}{c}\text { No. } \\
\text { Sample }\end{array}$} & $\begin{array}{c}\text { added } \\
(\mathrm{nM})\end{array}$ & $\begin{array}{c}\text { Founded } \\
(\mathrm{nM})\end{array}$ & $\begin{array}{c}\text { Recovery } \\
(\%)\end{array}$ & RSD $(\%)$ & $\begin{array}{c}\text { Founded } \\
(\mathrm{nM})\end{array}$ & $\begin{array}{c}\text { Recovery } \\
(\%)\end{array}$ & RSD $(\%)$ \\
\hline 1 & 25 & 24.59 & 98.36 & 3.1 & 25.40 & 101.6 & 0.059 \\
2 & 50 & 51.08 & 102.16 & 1.7 & 49.97 & 99.94 & 0.135 \\
3 & 75 & 74.90 & 99.86 & 2.6 & 75.09 & 100.12 & 0.031 \\
4 & 100 & 101.47 & 101.47 & 2.15 & 100.85 & 100.85 & 0.112 \\
\hline
\end{tabular}

*No. of measurements $\mathrm{n}=3$, ** According to USP 40- NF 35 
Table 5- Results of Analysis of Variance of Modeling the Clox Removal Using

MWCNT/CC.

\begin{tabular}{ccccccc}
\hline & Sum of & & Mean & $\boldsymbol{F}$ & p-value & \\
\hline Source & Squares & df & Square & Value & Prob $>$ F & \\
Model & 25742.13 & 14 & 1838.723 & 15.93835 & $<0.0001$ & significant \\
A-pH & 2281.969 & 1 & 2281.969 & 19.78048 & $<0.0001$ & \\
B-time & 3693.802 & 1 & 3693.802 & 32.01847 & $<0.0001$ & \\
C-MWCNT & 3901.605 & 1 & 3901.605 & 33.81975 & $<0.0001$ & \\
D-MWCNT/CC & 5422.985 & 1 & 5422.985 & 47.00731 & $<0.0001$ & \\
AB & 3921.19 & 1 & 3921.19 & 33.98951 & $<0.0001$ & \\
AC & 944.3286 & 1 & 944.3286 & 8.185594 & 0.6727 & \\
AD & 3835.016 & 1 & 3835.016 & 33.24254 & 0.0919 & \\
BC & 5098.671 & 1 & 5098.671 & 44.19611 & 0.0019 & \\
BD & 1227.58 & 1 & 1227.58 & 10.64087 & 0.4359 & \\
CD & 4480.821 & 1 & 4480.821 & 38.84049 & $<0.0001$ & \\
A $^{\wedge}$ & 12312.72 & 1 & 12312.72 & 106.7286 & $<0.0001$ & \\
B`2 $^{\wedge}$ & 997.8857 & 1 & 997.8857 & 8.649836 & 0.0101 & \\
C2 & 9828.36 & 1 & 9828.36 & 85.19383 & $<0.0001$ & \\
D`2 $_{\text {Residual }}^{\wedge}$ & 302.9624 & 1 & 302.9624 & 2.626128 & 0.1259 & \\
Lack of Fit & 1730.471 & 15 & 115.3647 & & & \\
Pure Error & 210.7278 & 5 & 42.14555 & & & \\
Cor Total & 27472.6 & 29 & & & & \\
\hline
\end{tabular}


Table 6. Comparison of performance of the suggested adsorbent and proposed method for study of the antibiotic removal.

\begin{tabular}{|c|c|c|c|c|c|c|c|c|}
\hline \multirow[b]{2}{*}{ adsorbent } & \multirow[b]{2}{*}{ analyte } & \multicolumn{2}{|c|}{ Adsorbent Specify } & \multicolumn{4}{|c|}{ Detection method } & \multirow[b]{2}{*}{ Ref } \\
\hline & & $\begin{array}{c}\text { BET } \\
\text { surface }\end{array}$ & Qmax & LOD & $\begin{array}{c}\text { Linear } \\
\text { range }\end{array}$ & Method & Recovery & \\
\hline MWCNT/CC & Clox & 31.377 & 295 & $8.0 \mathrm{nM}$ & $20-950$ & DPV & 98.3-101 & This work \\
\hline PPy-PA6-NFs & Clox & - & - & $\begin{array}{c}2.0 \\
\mathrm{ng} / \mathrm{mL}\end{array}$ & $\begin{array}{l}5.0-250 \\
\mathrm{ng} / \mathrm{mL}\end{array}$ & CE-DAD & $84.2-96.4$ & Li; 2019 \\
\hline MIP & Clox & & 280 & $36 \mathrm{nM}$ & $110-750$ & DPV & $98-100$ & Jafari; 2019 \\
\hline SWCNT/CC & Clox & 105.64 & 476 & 1.6 & $5.0-775.0$ & DPV & & $\begin{array}{l}\text { Golkarieh; } \\
2021\end{array}$ \\
\hline MWCNT & $\mathrm{TCN}$ & 221.9 & 253.38 & - & - & HPLC & - & Babaei; 2016 \\
\hline \multirow{3}{*}{$\begin{array}{c}\text { MWCNT/MIL } \\
-53(\mathrm{Fe})\end{array}$} & $\mathrm{TCN}$ & 60.17 & 364.3 & & & $\begin{array}{c}\text { UV } \\
\text { spectrophotometer }\end{array}$ & - & Xiong; 2018 \\
\hline & OTC & 60.17 & 325.5 & & & $\begin{array}{c}\text { UV } \\
\text { spectrophotometer }\end{array}$ & - & Xiong; 2018 \\
\hline & CTC & 60.17 & 180.6 & & & $\begin{array}{c}\text { UV } \\
\text { spectrophotometer }\end{array}$ & & Xiong; 2018 \\
\hline- & Clox & - & - & $\begin{array}{l}8-14 \\
\mathrm{ng} / \mathrm{L}\end{array}$ & - & HPLC/MS/MS & $83.9-95.9$ & Cha, 2006 \\
\hline- & Clox & - & - & 0.1 & $0.1-100$ & EIS & - & $\begin{array}{c}\text { Burmańczuk; } \\
2017\end{array}$ \\
\hline- & Clox & - & - & - & $30-65$ & HPLC & - & Najlaoui; 2019 \\
\hline
\end{tabular}

CE-DAD: capillary electrophoresis with a diode array detector (CE-DAD), TCN: tetracycline hydrochloride, OTC: oxytetracycline hydrochloride, CTC: chlortetracycline hydrochloride (CTC) 
Table 7. Kinetic parameters for Clox adsorption on MWCNT/CC

\begin{tabular}{ccccccc}
\hline & \multicolumn{3}{c}{ Pseudo-first order } & \multicolumn{3}{c}{ Pseudo-second order } \\
\cline { 2 - 6 }$q_{\max }($ exp. $)$ & \multicolumn{2}{c}{$\operatorname{Ln}\left(q_{e}-q_{t}\right)=L n q_{e}-k_{1} t$} & \multicolumn{2}{c}{$\frac{t}{q_{t}}=\frac{1}{k_{2} q_{e}^{2}}+\frac{t}{q_{e}}$} & \\
\cline { 2 - 7 } & $k_{1} \mathrm{~min}^{-1}$ & $\begin{array}{c}q_{e} \text { (calc.) } \\
\mathrm{mg} / \mathrm{g}\end{array}$ & $\mathrm{R}^{2}$ & $k_{2} \mathrm{~min}^{-1}$ & $\begin{array}{c}q_{e}(\text { calc. }) \\
\mathrm{mg} / \mathrm{g}\end{array}$ & $\mathrm{R}^{2}$ \\
\hline 296 & 0.0230 & 285.5 & 0.971 & 0.003 & 295.7 & 0.997 \\
\hline
\end{tabular}


Table 8 Isotherm parameters for Clox adsorption on MWCNT/CC.

\begin{tabular}{lcccccc}
\hline Isotherm Model & \multicolumn{2}{c}{ Langmuir } & \multicolumn{3}{c}{ Freundlich } \\
\hline Linear equation & \multicolumn{2}{c}{$\mathrm{C}_{\mathrm{e}} / \mathrm{q}_{\mathrm{e}}=\left(1 / \mathrm{bq}_{\max }\right)+\left(1 / \mathrm{q}_{\max }\right) \mathrm{C}_{\mathrm{e}}$} & \multicolumn{2}{l}{$\log \mathrm{q}_{\mathrm{e}}=\log \mathrm{K}_{\mathrm{F}}+(1 / \mathrm{n}) \log \mathrm{C}_{\mathrm{e}}$} \\
& $q_{\max }$ & $K_{L}$ & $\mathrm{R}^{2}$ & $K_{F}$ & $N$ & $\mathrm{R}^{2}$ \\
\hline & 296.8 & 0.142 & 0.993 & 0.874 & 1.275 & 0.981 \\
& & & & & & \\
\hline
\end{tabular}


Table 9: Thermodynamic parameters for the adsorption of Clox on MWCNT-CC

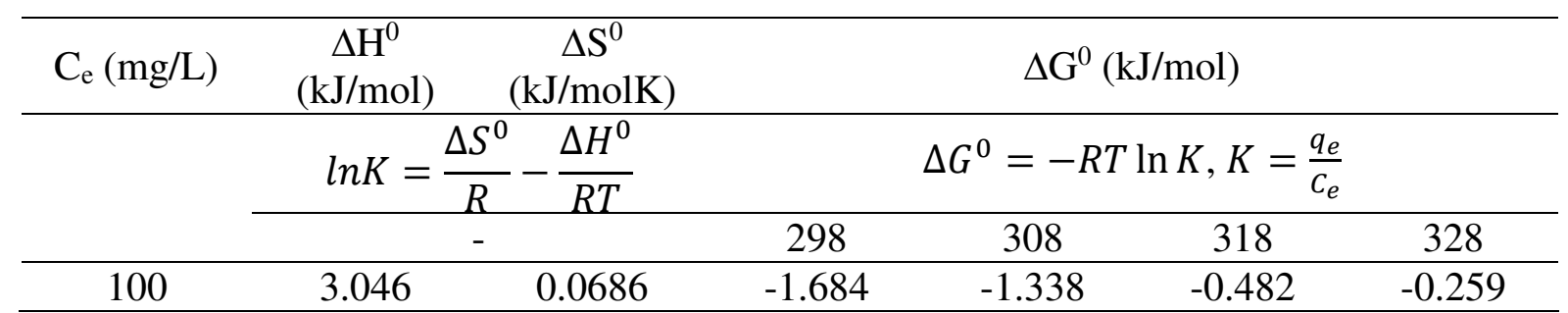

R: universal gas constant $\left(8.314 \mathrm{Jmol}^{-1} \mathrm{~K}^{-1}\right)$, T: absolute temperature (K), K: distribution coefficient. 


\section{Figures}

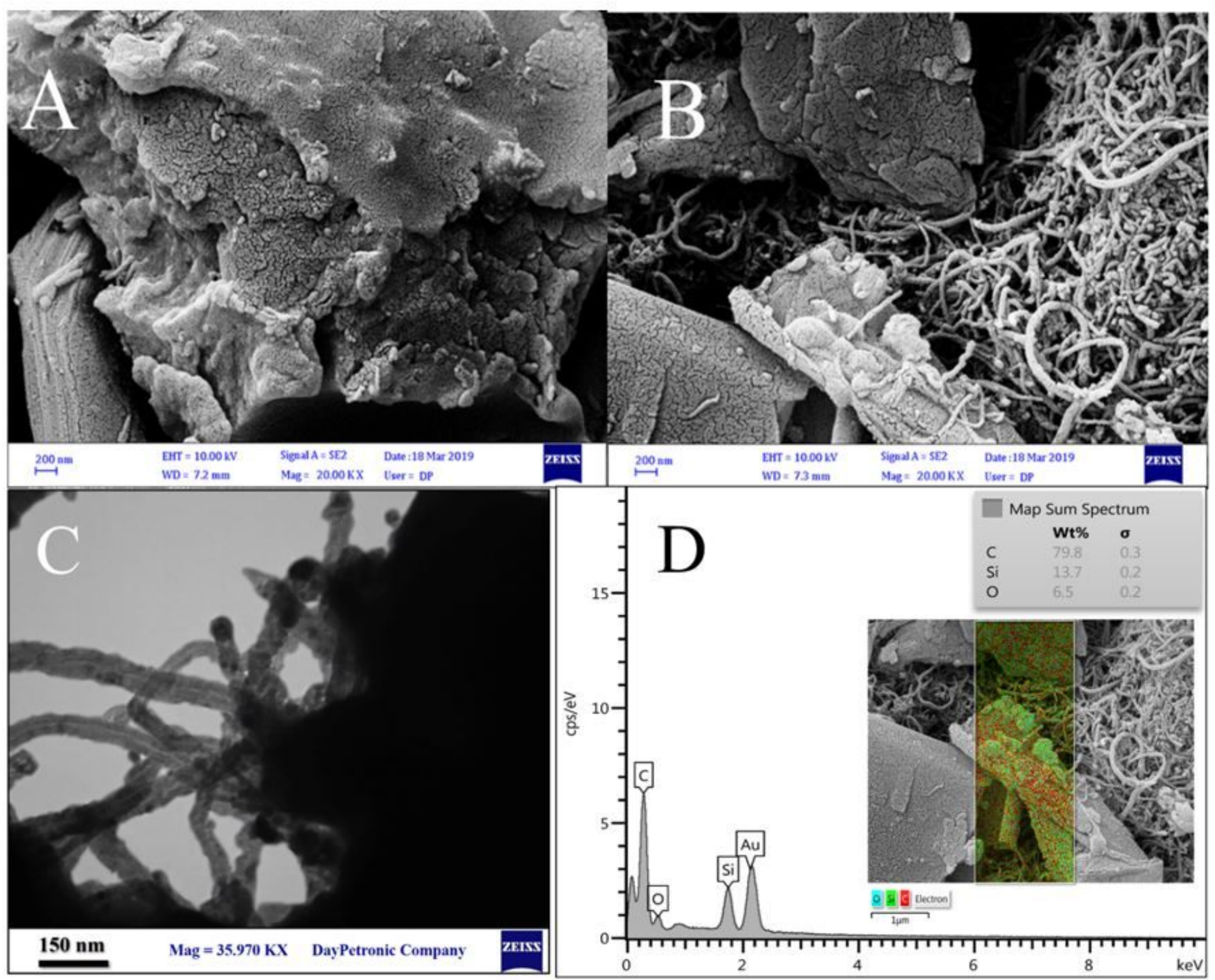

Figure 1

FESEM images of the A) carbon composite without MWCNTs and B) carbon nanocomposite containing MWCNTs, C) TEM image and D) Elemental analysis and mapping diagram of carbon nanocomposites containing MWCNTs. 

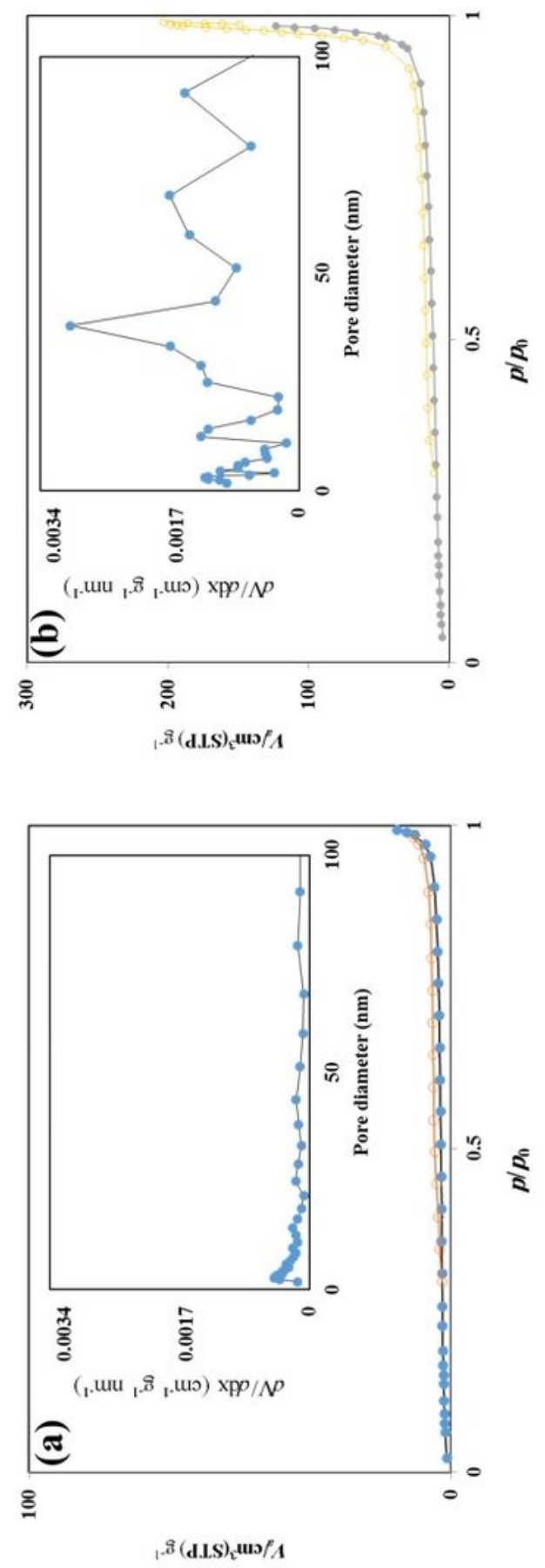

\section{Figure 2}

Diagram of N2 absorption-desorption for a) unmodified carbon composite, the inset is the calculated pore diameter distribution. b) MWCNTs-modified carbon nanocomposite. The insert is the calculated pore diameter distribution. 


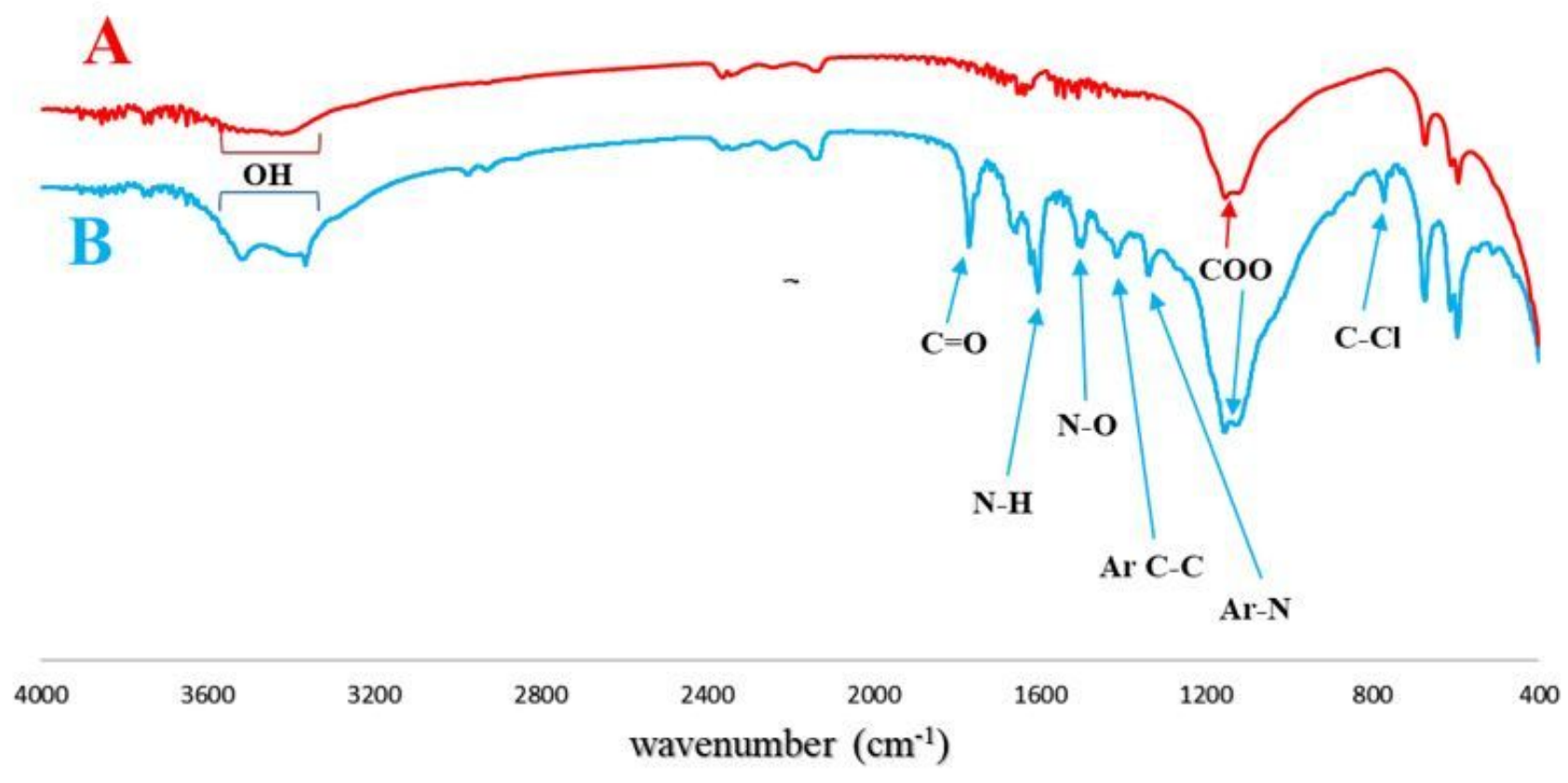

Figure 3

FTIR spectra of the MWCNT/CC before (A) and after (B) adsorption of Clox.



\section{Figure 4}

A) Cyclic voltammograms of modified SPCE in a solution containing $0.1 \mathrm{mM}$ of Clox in phosphate buffer with $\mathrm{pH}=7.0$. a) bare SPCE, b) GO modified SPCE, c) GNU/GO SPCE. B) CV responses of the SPCE in 1.0 $\mathrm{mM}[\mathrm{Fe}(\mathrm{CN}) 6] 3-/ 4-$ in a $0.1 \mathrm{M}$ phosphate buffer ( $\mathrm{pH}$ 7.0) for (a) the bare SPC electrode, (b) GO/SPCE, and (c) GNU/GO/SPCE. C) Differential pulse voltammograms of GNU/GO modified SPCE in the presence of different concentrations of Clox (20.0-950.0 nM) in 0.1 M buffer solution pH 7.0. D) Diagram of current variations in terms of concentration of Clox (20.0 -950.0 nM).
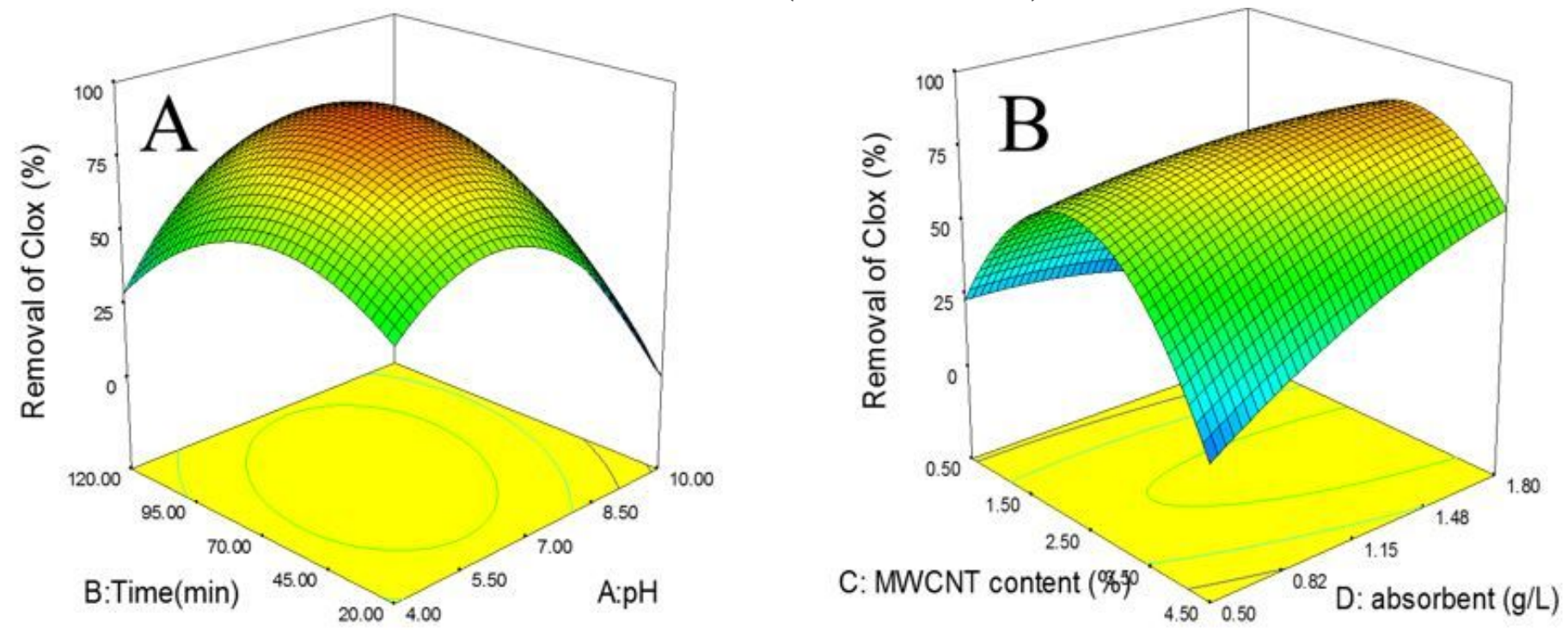

\section{Figure 5}

Three-dimensional response surface plots for interactive effect of the A) $\mathrm{pH}(4.0-10.0)$ and contact time (20-120 $\mathrm{min}$ ) at $3.21 \% \mathrm{wt} \mathrm{MWCNT} \mathrm{and} 1.31 \mathrm{~g} / \mathrm{L} \mathrm{MWCNT/CC,} \mathrm{B)} \mathrm{MWCNTs} \mathrm{(0.5} \mathrm{-} 4.5 \% \mathrm{wt}$ ) and carbon nanocomposite $(0.5-1.8 \mathrm{~g} / \mathrm{L})$ on removal efficiency at the $\mathrm{pH}=5.0$ and contact time $67 \mathrm{~min}$. 




Figure 6

Cycle stability of MWCNT/CC during 6 cycle for Clox adsorbent.

\section{Supplementary Files}

This is a list of supplementary files associated with this preprint. Click to download.

- supplymentalFile.docx 